\title{
Inspirar luz, animar figuras ${ }^{1}$
}

\author{
Insufflare luce, animare figure \\ Blowing Light, animating Puppets
}

Cristina Grazioli ${ }^{2}$

Tradução $0^{3}$ : Berilo Luigi Deiró Nosella ${ }^{4}$ 


\section{Resumo}

$O$ artigo segue o pressuposto do potencial de "animação" pela luz, oferecendo um reconhecimento de possíveis significados da relação luz / figura. Diferentes exemplos desta paisagem serão abordados: desde as consonâncias entre os dois territórios, passando pelas relações dramatúrgicas mais íntimas, até o conceito de "atores de luz".

Palavras-chaves: Luz; figura; animação; atmosfera

\section{Sommario}

L'articolo muove dal presupposto della potenzialità di "animazione" da parte del fattore luminoso, offrendo una ricognizione di alcune delle possibili accezioni della relazione luce/figure. Si offrono esempi diversi di questo paesagio: dalle consonanze tra i due territori, alle più intime relazioni a livello dramma-turgico, alle concezioni di "attori di luce".

Parole-chiave: Luce; figure; animazione; atmosfera

\section{Abstract}

The article considers the assumption of the potential of "animation" by light, proposing a survey of some of the possible meanings of the relationship between light and puppet. Different examples of this landscape are approached, from the consonances between the two territories, to the more intimate relationships on a dramaturgical level, to the concept of a "performer" made of light.

Keywords: Lighting; puppetry; animation; atmosphere

Este artigo tem como ponto de partida uma breve contribuição publicada em Poétiques de l'illusion. Dialogues contemporains entre marionnette et magie, Alternatives Théâtrales: Liège 2018, p. 86-89. É complementado aqui por outros materiais que foram objeto de seminários e aulas (na Sorbonne Nouvelle Paris 3 em 2009/2010; na Unirio, Rio de Janeiro em agosto de 2015; na Universidade Paul Valéry de Montpellier em fevereiro de 2016, entre outros).

\footnotetext{
2 Professora doutora associada, Universidade de Pádua (I). As suas principais áreas de pesquisa se se focam nas relações entre Teatro e Artes Visuais, dramaturgia alemã do início do século XX, Estética da Marionete e lluminação Cênica.
}

Professor at the University of Padua (I). The lines of investigation of her researches focus on the relationship between Theatre and Visual Arts, German Drama at the beginning of the 20th century, Aesthetics of the Marionette, Lighting in the Theatre.

Professore Associato all'Università di Padova (I). Le sue principali linee di ricerca si concentrano sulle relazioni tra Teatro e Arti Visive, sulla drammaturgia tedesca del primo Novecento, sull'Estetica della Marionetta, sull'llluminazione scenica.

3 Revisão da tradução: Isa Fernanda Vianna Carvalho.

Prof. Dr. - Curso de Graduação em Teatro e do Programa de Pós-graduação em Artes Cênicas - Universidade Federal de São João del Rei (UFSJ). berilonosella@ufsj.edu.com 


\section{Les mains de lumière. Um ator irradiante luz}

A questão da natureza e das manifestações da luz surge juntamente à questão das possibilidades do ver, da escolha de um ângulo do visível, do esconder, do revelar ou sugerir, do evocar e do desmascarar.

A visão e o olhar não podem ignorá-la. No entanto, ou talvez justamente por suas evidências macroscópicas, a luz é o elemento menos estudado em sua especificidade entre os códigos do espetáculo. Apenas nos últimos anos, se nota uma maior atenção nesse sentido ${ }^{5}$. Ainda mais raro é o reconhecimento da iluminação no contexto do universo das figuras (bonecos, fantoches, sombras e todos os gêneros específicos desses derivados); este é também um território que tem sido objeto de atenção renovada nos últimos tempos, também em virtude de um deslocamento e ampliação do estatuto de "Figura"6, que deve ser levado em consideração para as reflexões que aqui propomos. Uma cuidadosa consideração e combinação desses dois temas, luz e figuras, revela uma complexa rede de vínculos e cumplicidade - e não apenas em relação à estética do contemporâneo. É significativo que, há muitos anos, Didier Plassard tenha dado o título de Les mains de lumière a uma preciosa antologia de testemunhos sobre a arte da marionete (Plassard, 1996).

A expressão foi emprestada de Henri Gouhier. Parece-nos útil retomar as reflexões do filósofo. Em 1952, Gouhier publicava Le théâtre et l'existence (Gouhier, 2004), um ensaio no qual desenvolvia as questões propostas em L'Essence du théâtre (1943; Gouhier, 1968), formulando considerações importantes sobre as relações entre a cena e o pensamento filosófico. Uma parte do capítulo L'existence sur la scène é dedicada à marionete (La Marionnette, Gouhier, 1968, p. 119-127). O discurso se apoia na crença de que a marionete não suprime o ator, mas funciona como uma forma particular de existência, ou melhor, de "presença". O marionetista é, para todos os efeitos, um ator (o que é óbvio hoje, mas talvez não o fosse em 1952).

O papel dele não se compara ao de um operador de lanterna mágica, um técnico silencioso e externo à cena. Ao que sua mão puxa os fios ou serve de corpo para o fantoche, é uma mão inteligente que dá vida graças à sua inte-ligência e movimento ao mesmo tempo. Ao que sua voz fale acima ou abaixo dos atores de madeira e de sua comédia, é uma voz humana, que dá alma por meio dessa humanidade, ao mesmo tempo que anima. É como dizer que uma presença é interna à ação e que a ação irradia uma presença; é como dizer que $\circ$ teatro de marionetes também exige a presença ativa do ator. (Gouhier, 1968, p. 120). ${ }^{7}$

São evidências disso os projetos realizados nos últimos anos: Lumière de Spectacle, Université di Lille; Dire Luce. Le parole e le cose che illuminano la scena, Universidade de Pádua.

Cf. o importante trabalho de Julie Postel, Présences de la Marionnette contemporaine: figure, figuration, défiguration, Thèse de Doctorat dirigée par Amos Fergombé, Université Polytechnique Hauts-de-France, Valenciennes, 2019; e a dissertação de mestrado de Lorenzo Diofili, Corpi, figure e spazio: la poetica di Gideon Obarzanek nel panorama delle arti performative dalle avanguardie storiche al XXI secolo (ou Corpos, figuras e espaço: a poética de Gideon Obarzanek no panorama das artes cênicas da vanguarda histórica ao século XXI, em tradução da autora), orientada por Cristina Grazioli na Universidade de Pádua.

Son rôle n'est nullement comparable à celui du manipulateur qui fait marcher la lanterne magique, mécanicien silencieux et en dehors du jeu. Que sa main tire les ficelles ou serve de corps à la poupée, elle est une main intelligente qui donne la vie par cette intelligence en même temps que le mouvement. Que sa voix parle au-dessus ou au-dessous des comédiens de bois et de leur comédie, elle est une voix humaine qui donne une âme par cette humanité en même tant que 
E ainda:

[...] tudo o que resta do ator é uma presença sem contornos e quase impes-soal, o calor irradiando de uma fonte oculta, a luz caindo de uma estrela anô-nima. O imaginário visual captura o espectador dentro do espetáculo e, para ele, Guignol existe mais do que a mão sem a qual Guignol não existiria. (Gou-hier, 1968, p. 123). ${ }^{8}$

O efeito que a marionete exerce não suprime a presença do ator, mas causa um desvio de seu corpo em relação à dimensão do espetáculo, de forma que as formas e o rosto que deram vida à imaginação sejam esquecidos.

A marionete é "fantôme" (Gouhier, 1968, p. 125), dividida entre a existência física e a imaginária. Uma "ética profissional" diferente emerge com esse ator escondido pelas mãos de luz ("aux mains de lumière", Gouhier, 1968, p. 125-1269).

"Ação que irradia presença", "calor irradiando de uma fonte oculta", "luz caindo de uma estrela anônima", "o ator com as mãos de luz": o campo semântico de Gouhier emana luz.

É claro que Gouhier não pretende falar literalmente sobre iluminação cênica, mas a terminologia e as imagens postas em prática são significativamente aquelas da luz. Nosso olhar atual capta sugestões e confirmações úteis.

\section{Pontos de referência: consonâncias}

Relendo poéticas que foram marcos do século XX, como as de Maeterlinck ou de Craig, hoje as assonâncias entre o universo da luz e da sombra e o paradigma da Marionete não passam despercebidas; os dois autores, diferentes entre si, marcam decisivamente a qualidade desse parentesco entre a matéria da luz e figura ${ }^{10}$. No final do século XIX, Maeterlinck escreve dramas "para marionetes" e, ao mesmo tempo, publica uma das mais famosas declarações de apelo pela substituição do ator em carne e osso pela marionete (Menus propos, 1890). O autor flamengo refere-se a "une ombre, un reflet, une projection de formes symboliques" (Maeterlinck, 1890, p. 335) como equivalente às marionetes. Craig, como sabemos, é responsável por algumas das reflexões mais ricas do século XX, tanto sobre as marionetes quanto sobre a

\footnotetext{
l'animation. C'est dire qu'une présence est intérieure à l'action et que l'action fait rayonner une présence; c'est dire que le théâtre de marionnettes exige, lui aussi, la présence active de l'acteur. (Tradução da autora do francês para o italiano, e nossa do italiano para o português).

8 [...] de l'acteur il ne reste qu'une présence sans contours et presque impersonnelle, chaleur rayonnant d'une source cachée, lumière tombée d'une étoile anonyme. L'imagerie visuelle attache le spectateur au spectacle et, pour lui, Guignol existe plus que la main sans laquelle Guignol n'existerait pas (Tradução da autora do francês para o italiano, e nossa do italiano para o português).

9 Ele também considera essencial "a metamorfose que garante a presença" (ibid., p. 126).

10 Cf. Grazioli, 2013.
} 
luz no palco. Em seu famoso ensaio The Actor and the Übermarionette (1908), ele sobrepõe "shades", "shadows", "spirit", "glance" à ideia de Marionete (Craig, 1908, p. 9). ${ }^{11}$

Não é por acaso que, numa época mais próxima de nós, ao montarem os textos de Maeterlinck, vários diretores tenham explorado em primeiro lugar o potencial da luz: como exemplo, Claude Régy, em colaboração com Dominique Bruguière, Denis Marleau, com atores desmaterializados graças às novas tecnologias ${ }^{12}$. No recente L'Enfant, de Elise Vigneron (Théâtre de L'Entrouvert) (Figura1), La mort de Tintagiles é traduzido no palco pela chave da instabilidade, da frágil fronteira entre certo e incerto, real e invisível, dizível e indizivel; a expressão dessa fragilidade é confiada à concepção do espaço, em que a imersão no escuro e a criação do percurso dramatúrgico, graças à presença na luz, são fundamentais e "geradoras" de uma imagem dramatúrgica ${ }^{13}$.

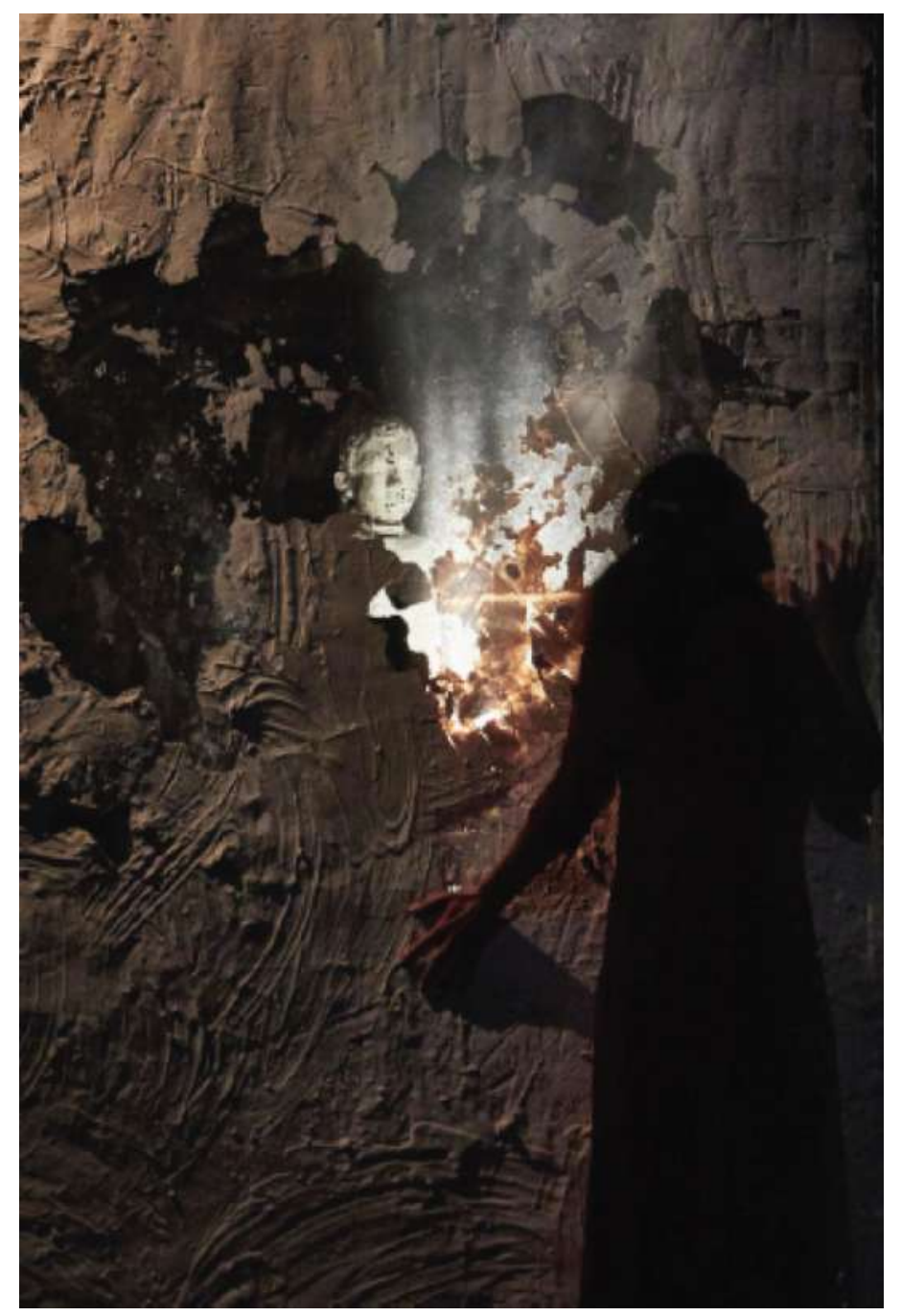

Figura 1 - L'enfant. Théâtre de l'Entrouvert, 2019. Foto: Christophe Loiseau Direção: Elise Vigneron. Criação das luzes e dispositivos de cena: Benoît Fincker

\footnotetext{
11 Escrito em Florença em 1907.

12 Cf. Modernité de Maeterlinck. Denis Marleau, "Alternatives théâtrales", n’ 73-74, julho de 2002; ver a resenha de Pierre Piret disponivel em https://journals. openedition.org/textyles/829, último acesso em $1^{\circ} \mathrm{dez}$. 2019, na qual, no entanto, não se enfatiza a dimensão da luz, mas de novas tecnologias.

13 Apresentado no Festival di Charleville-Mézières 2019, http://lentrouvert.com/lenfant, última consulta em 9 dez. 2019.
} 
Desde os anos 1920, Richard Teschner, um artista pouco estudado, combina pesquisa luminística e inovação na arte de marionetes, realizando concretamente essa conjuntura: graças a dispositivos altamente refinados de fontes de luz e superfícies refletivas (espelhos), mas também construindo marionetes de maneira a torná--las receptivas à luz (deixando os olhos vazios, por exemplo), ele alcança resultados extremamente originais ao dar às figuras uma presença misteriosa e evocativa de outros mundos (Jamain, 2018).

Hoje, vários artistas contemporâneos treinados 'na marionete' têm alta consideração pelo lado luminístico. Mas também é surpreendente que um artista 'da luz' como Bob Wilson compartilhe tantos momentos de reflexão sobre marionetes e supermarionetes.

Se já em um artigo de 2000 foram sugeridas assonâncias (Gaudé, 2000), é ine-vitável mencionar a esse respeito uma de suas últimas criações: a felicíssima con-juntura Robert Wilson/Isabelle Huppert em Mary said what she said (2019) sugere uma declinação do presságio craighiano. Demiurgo, Bob Wilson; Supermarionete, o Huppert; os fios: a luz. E, acima de tudo, uma voz que habita o corpo do intérprete tão profundamente que se torna a voz do Outro (também graças ao uso do som, to-talmente entrelaçado com a dramaturgia).

\section{Animar coisas}

Dadas essas coordenadas de referência, de modo algum exaustivas dos possíveis exemplos que demonstram as consonâncias entre o mundo das figuras e o universo da luz, empreendemos a tentativa de desenhar um possível mapa, necessariamente genérico e incompleto, das áreas de sobreposição e interseção entre esses dois territórios, ambos sujeitos a deslizamentos e mudanças, evoluções e contaminações durante o século $X X$ e, cada vez mais frequentemente, na paisagem contemporâ-nea. Notamos, em particular, a complexidade do termo "Marionete", principalmente a partir da vanguarda histórica, na segunda metade do século XX e hoje mais do que nunca ${ }^{14}$, momento em que essa expressão depende de uma gama de possibilidades que implicam na alteração da presença e em seu deslocamento para fora do corpo, no espaço e nas relações que estabelece.

\footnotetext{
14 Inúmeras intervenções relacionadas a essa 'extensão' da definição de 'marionete', especialmente no contexto francês. A título de exemplo, citamos: Marionnette, Corps-frontière, études réunis par Hélène Beauchamp, Joëlle Noguès et Élise Van Haesenbroeck, Artois Presse Université, Arras, 2016.
} 
Partiremos da questão (também entendida como "quête") que parece imprescindível para ambos os territórios: a animação. Uma palavra complexa já em sua raiz etimológica. Um termo que foge do controle, com diferentes conotações a depender dos contextos.

Estamos interessados no seu significado mais simples, o do processo de dar vida a algo que, por si só, não está vivo: em muitas línguas "animar" significa "dar vida", mas também "dar a aparência de vida"; assim como equivale a "doar vida" e ao mes-mo tempo a "trazer à luz"; e ainda a "transmitir movimento". Os vínculos semânticos entre luz, vida, dinamismo, mas também aparência de vida (ilusão) são significativos. ${ }^{15}$

É o ponto de origem do conceito e da prática constitutiva de cada técnica de manipulação; por outro lado, e também pelas implicações semânticas supracitadas, 'animar' também lembra o momento fundamental da reflexão moderna sobre a con-cepção de luz em cena. O ponto de partida neste caso é o pensamento essencial de Adolphe Appia: para o diretor, ciente de um uso apropriado da luz, o grande teórico da cena no início do século XX escreve, "le tableau ne sera donc plus, à aucun stade de vision, un agencement of peinture unanimé, mais il sera toujours animé" (Appia, 1983-1992, II, p. 351). A dialética animado/inanimado é central nas definições do pa-pel da luz e percorre muitas páginas dos escritos do artista de Genebra. Corpo do ator, objetos, espaço, cenografia vivem apenas se animados pela luz e sombra. O elemento arquitetônico da escada, que em breve será rejeitado por Craig no famoso projeto The Steps, é emblemático desse 'ganhar vida' do espaço e da arquitetura ${ }^{16}$, agora temas portadores de dramaturgia. E, ao mesmo tempo, conferindo a um su-jeito 'não humano' a qualidade de presença dramatúrgica, a relação 'ativa' entre arquitetura e ação recoloca em jogo o complexo de questões relacionadas às figuras.

Forte e cheio de consequências para todo pensamento sobre a luz que está por vir, um germe dessa ideia de uma luz 'vivificante' já é encontrado em épocas ante-riores, com as devidas distinções contextuais e como pronúncia de exceção. Pietro Gonzaga, cenógrafo italiano ativo em São Petersburgo no final do século XVIII, es-creve em um valioso ensaio sobre a inseparabilidade entre visão e escuta na obra do cenógrafo (1807):

Também podemos adicionar a variante "animista"; cf. além da referência de Max Lébegue. 
[...] assim como o ar sonoro não age de acordo com o sentimento a menos que seja artisticamente vivificado pelo músico, a luz não passa de brilho a não ser que seja retrabalhada, por assim dizer, em fantasma da superfície dos objetos que atinge, e devolvida aos olhos com maior velocidade e precisão [...]. Agora, o cenógrafo inteligente pode tirar o máximo proveito da massa de luz que existe entre o espetáculo e o espectador, se souber preparar artistica-mente as superfícies das cenas para enviar de volta os raios de luz transforma-dos em imagens ilusórias. ${ }^{17}$

A respiração que dá a vida sobre a qual Appia comenta, invisível, porém precisamente concebida e materialmente moldável, parece-nos relacionada a uma atmosfera, ou - para dizer com Rilke - a uma Melodia das coisas, que atua como uma amálgama entre as presenças cênicas e é uma garantia do evento de comunicação, compartilhamento do espaço e do movimento entre estes (corpos, objetos, espaço) e entre eles e os espectadores; uma melodia que se assemelha à luz e à marionete.

A referência a Rilke é mais do que uma sugestão, uma vez que o poeta das Elegie duinesi é um dos artistas que refletiu mais profundamente sobre as Figuras. $O$ escopo das "Coisas" como presenças se desenrola, entre outras coisas, na reflexão sobre o espaço atmosférico, uma melodia que as une e que é substanciada pela luz. O poeta escreve em um artigo de 1898:

É como se, no elenco de personagens, houvesse um guarda-roupa, um es-pelho, um som e muitas coisas mais sutis, suaves e ainda mais discretas. Na vida, tudo tem o mesmo valor: e uma coisa não vale menos que uma palavra, um perfume ou um sonho. Essa nivelada dignidade também deve se impor ao teatro. (Rilke, 1995, p. 70). ${ }^{18}$

Até as Coisas inanimadas são presenças, dotadas de habilidades de relacionamento e não basta que dois ou três homens se encontrem para estarem juntos. "São como marionetes cujos fios são operados por mãos diferentes. Só quando uma única mão os move, uma 'comunhão' os atinge do alto", fazendo-os agir (Rilke, 1995, p. $77)^{19}$.

\footnotetext{
16 As afirmações de Craig sobre o status de 'personagem' da arquitetura, da 'ação' dos movimentos do espaço, criados pelas sombras são decisivas para nosso discurso.

[...] comme l'air sonore n'opère rien sur le sentiment, s'il n'est pas agité artistement par l'adresse du musicien, ainsi la lumière n'est simplement que du jour, si elle n'est pas travaillée, pour ainsi dire, en fantôme par la surface des objets dans lesquels elle frappe, et en est renvoyé à l'œil avec la plus grande vitesse et exactitude [...]. Or, le décorateur intelligent, pour tirer tout le parti qu'il veut de la masse de lumière qui se trouve entre le spectacle et le spectateur, s'il sait artistement préparer les surfaces des coulisses de manière à nous renvoyer les rayons lumineux transformés en images illusoires. (Gonzaga, 1807, p. 52-53). (Tradução da autora do francês para o italiano, e nossa do italiano para o português).

18 "Als ob im Personenverzeichnis stünde: ein Schrank, ein Glas, ein Klang und das viele Feinere und Leisere auch. Im Leben hat alles denselben Wert, und ein Ding ist nicht schlechter als ein Wort oder ein Duft oder ein Traum. Diese Gerechtigkeit muß auch auf der Bühne nach und nach Gesetz werden" (Rilke, 1955-1966, v. 10, p. 442).

${ }^{19}$ Sie sind wie Marionetten deren Drähte in verschiedenen Händen liegen. Erst wenn eine Hand alle lenkt, kommt eine Gemeinsamkeit über sie (Rilke, 1955-1966, v. 10, p. 416).
} 


\section{Atores de luz}

Se os variados exemplos que mencionamos se referem à poética e às concepções de arte cênica, a segunda zona de interseção é delineada com base em afinidades formais e encontra relações e numerosos testemunhos em antecedentes históricos, no âmbito daquelas presenças que chamei em outras ocasiões de "atores de luz": uma grande família de figuras que, apesar da diversidade de significados, modalidades, concepções, tomam forma (e espaço) graças à luz ou à sombra. Para se ater às práticas espetaculares ${ }^{20}$, uma visão geral considera a princípio as imagens da lanterna mágica, provavelmente já utilizadas no teatro barroco (Grazioli, 2008, p. 99-114; Grazioli, 2008a, p. 11-22), juntamente das muitas presenças fantasmáticas dos chamados "gêneros ópticos" - não esqueçamos que a raiz de fantasma é $\varphi \tilde{\omega} \varsigma$, luz; depois, a fantasmagoria do século XIX e todos os truques que dela derivam para encenar os espectros (Pepper's Ghost, a patente mais bem-sucedida desenvolvida por Henri Dircks na década de 1840). Sabe-se que Giuseppe Verdi, artista atento à complexidade da encenação, pediu ao cenógrafo Sanquirico que encontrasse uma solução para a aparição do fantasma de Banquo em Macbeth, tomando a fantasmagoria como modelo (Conati, 1981); mas também a "ombromania" (jogo de sombras com as mãos); e o infinito universo de muitas tradições dos teatros de sombras, mais ou menos desmaterializadas, mais ou menos 'sombrias', até o teatro de sombras contemporâneo.

Seriam marionetes? Em épocas passadas, certamente não, mas, sim, uma 'espécie' de presença cênica diferente daquela do ator em carne e osso; de uma alteração do corpo (ou de sua visão) que será uma premissa fértil para as poéticas e práticas que estão por vir. ${ }^{21}$

Ao entrar no século $X X$, multiplicam-se as figuras que pressionam para fora do palco o ator em carne e osso nas cenas sonhadas pela vanguarda histórica. Já não se trata de mera semelhança técnica, mas de concepções que renovam o estatuto de presença: Prampolini em Scenografia e coreografia futurista (1915, em "La Balza futurista") oferece flashes luminosos e "atores-gás coloridos"; Fortunato Depero, em Colori, anima sons e ruídos em um quarto-cubo azul, muito vazio. Quatro "individualidades abstratas" são movidas mecanicamente por fios invisíveis e cada "cor" tem uma voz com características diferentes (Depero, 1916). Nas sínteses futuristas, as luzes substituem as personagens; Giacomo Balla faz com que os sólidos de luz colorida atuem em Feux d'artifice e os artistas da Bauhaus experimentam os cromatismos da luz em movimento com materiais refletidos que transfiguram os

Os exemplos são inesgotáveis quando não limitados a gêneros espetaculares, mas expandidos a imagens e metáforas literárias ou filosóficas, de Platão em diante.

21 Não é por acaso que os duplos virtuais da empresa canadense Lemieux-Pilon são chamados de "fantasmagoria tecnológica"; cf. Maurin, 1996; na mesma edição de Puck, útil como um todo para as questões que estamos abordando, ver também Béatrice Picon-Vallin, La scène, l'acteur et ses doubles projetés, p. $32-38$. 
corpos (e impossível não lembrar como, mesmo fora das cenas, a associação desencadeada dos objetos de Man Ray (Figura 2), metamorfoseados em humanos pelas sombras, ou pela lâm-pada que 'interpreta' a L'Americaine de Picabia?).

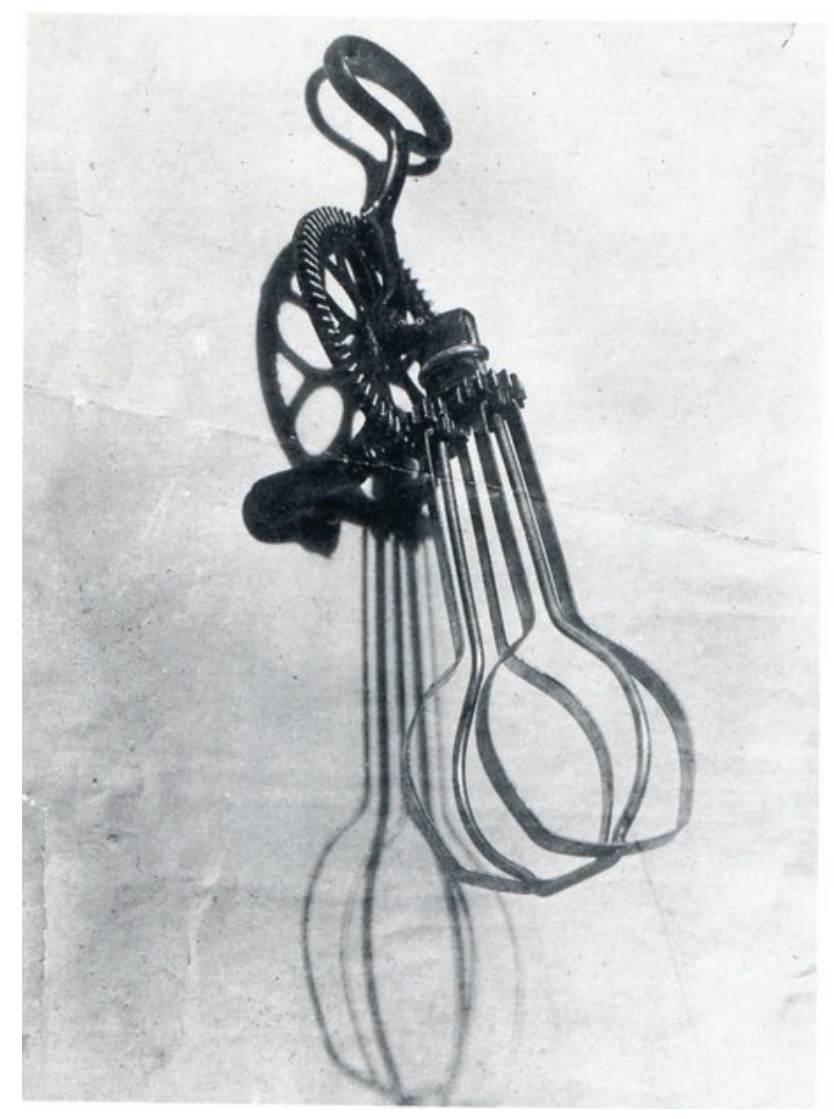

Figura 2 - Man Ray, L'homme, 1918. Collezione privata (Vera et Arturo Schwarz, Milan)

As inovações no contexto do Teatro di Regia andam de mãos dadas, especialmente na Alemanha: a partir da década de 1920, projeções (de imagens estáticas ou em movimento) começaram a desempenhar a função de produzir uma qualidade diferente da presença cênica; são, portanto, usadas com um escopo dramatúrgico. Piscator oferece numerosos exemplos a esse respeito: basta lembrar que, para a encenação de Fahnen di Paquet (1924) no Berliner Volksbühne, o prólogo exibe uma figura 'épica' que apresenta as personagens: Piscator, a princípio, pensou em exibi-las na forma de marionetes, depois transformou essa ideia na solução da projeção cinematográfica; então, por razões técnicas, decidiu-se por slides, de modo que o apresentador indicaria suas fotografias na tela (Mildenberger, 1961, p. 195) (um pouco como os contadores de histórias de antigamente). O filme, ou a imagem da luz proje- 
tada, obviamente serve para diferenciar uma qualidade de presença (e é significativo que Piscator hesite entre a projeção e as marionetes). ${ }^{22}$

Prosseguindo para a metade do século $X X$, não podemos ignorar um mestre da luz que concebe a projeção cinematográfica em cena como uma maneira de questionar a presença unívoca da personagem, de 'alterar' sua identidade por meio da multiplicação: na experimentação da Laterna Magika (este é o nome do famoso dispositivo que mais tarde designará seu teatro), Joseph Svoboda cria duplos luminosos e etéreos dos atores em cena. A partir de então, os exemplos são incontáveis, seja por avanços tecnológicos que por mudanças na poética e na dramaturgia: é impossível listar todas as imagens do século XX de presenças na ausência, pairando no limiar entre visível e invisível: imagens de vídeo que interagem com os atores (Giorgio Barberio Corsetti em colaboração com o Studio Azzurro), presenças refinadas possibilitadas em enredos de luz pelas novas tecnologias (um exemplo de poesia rara são as criações de Shirazeh Houshiary e as luzes de Lucy Carter para Amu (Figura 3), de Wayne McGregor, 2005)23. Ou ainda a cena multimídia de Robert Lepage, "corpo ex-pandido" graças à luz e às tecnologias ${ }^{24}$ ou ao uso da pintura digital, por exemplo, nas criações de Tam Teatromusica ${ }^{25}$ (Figura 4).

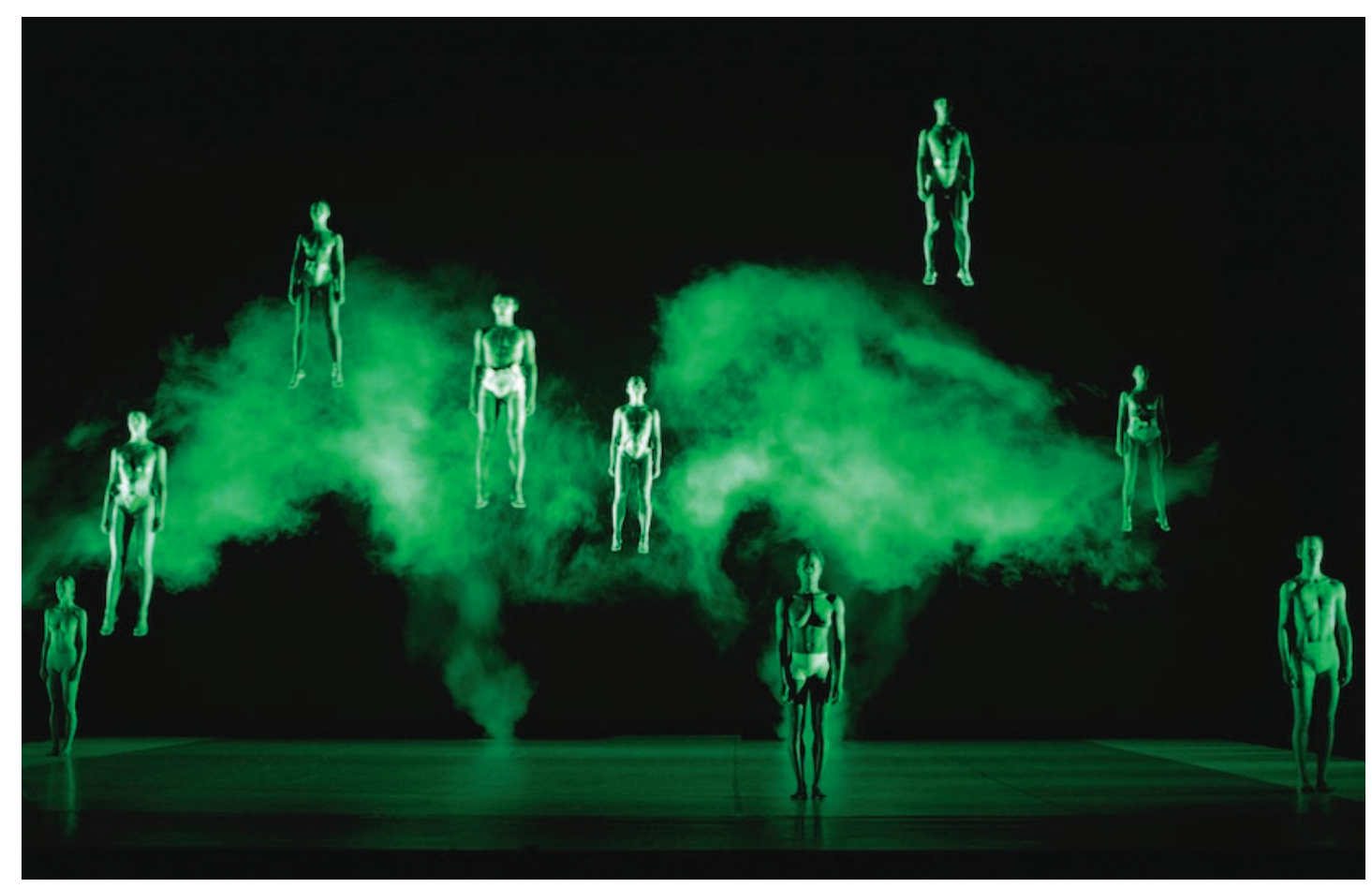

Figura 3 - Amu, Company Wayne McGregor (previously Wayne McGregor | Random Dance), 2005. Foto: Ravi Deepres; Wayne McGregor, Shirazeh Houshiary, Lucy Carter

\footnotetext{
22 Referência a Grazioli, 2017.

23 Veja a animação Veil, usada no espetáculo com Wayne McGregor, http://www.shirazehhoushiary.com/animation/\#project3, último acesso em 9 dez. 2019.

24 Cf. http://www.annamonteverdi.it/digital/integrazione-cinematografica-nel-teatro-di-robert-lepage-le-polygraphel, último acesso em 9 dez. 2019.

25 Entre os muitos exemplos, consulte Scritto dentro, https://nuovoteatromadeinitaly.sciami.com/tam-teatromusica-scritto-dentro-2013/, último acesso em 10 dez. 2019.
} 


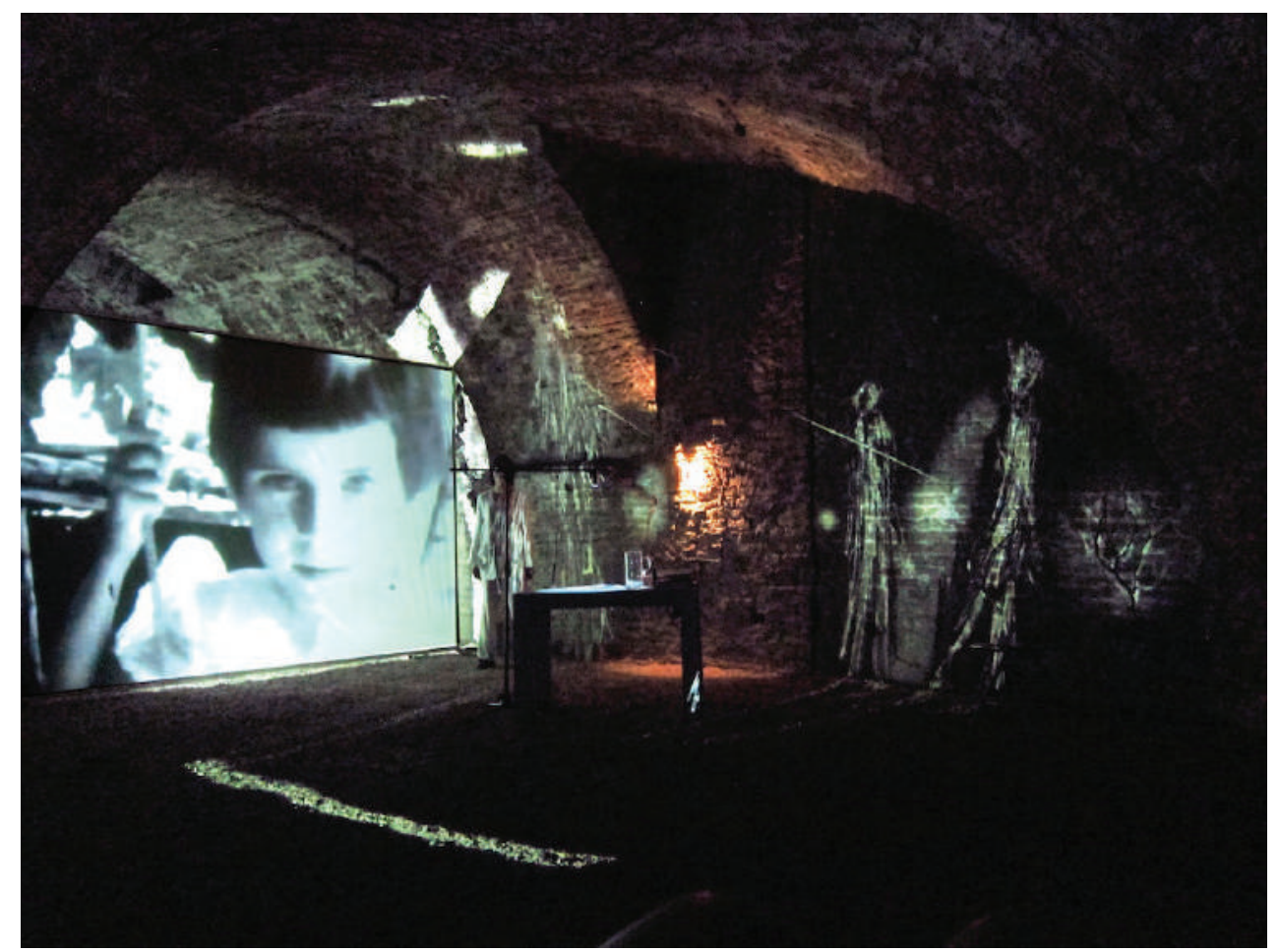

Figura 4 - Scritto Dentro, Pierangela Allegro e Michele Sambin, TAM Teatromusica, 2013. Foto: Claudia Fabris

\section{Dramaturgias: a presença de figuras ausentes}

Em nível de concepção dramatúrgica, uma referência imprescindível é Beckett, um dos autores, a nosso ver, de maior consonância com muitas poéticas contemporâneas do teatro de marionetes ${ }^{26}$; ao mesmo tempo, em muitos de seus textos, Beckett constrói a ação dramática com base em personagens que incorporam a ausência, que se torna perceptível graças à luz. Pensemos em Neither, Rockaby, ou mesmo em contos como Sans, Le Depepleur, ou o emblemático Pas moi: textos em que os extraordinários 'vazios' de personagens são preenchidos pela substância luminosa, ou cujas existências se fazem notáveis de forma indissociável da escuridão. Inúmeras companhias de teatro de figura se inspiraram nesse dramaturgo irlandês, além dos artistas que exaltaram essa dimensão da presença incerta graças às finas concepções de luz. Na "vídeo-ambientação" Neither (Figuras 5-5B), do Studio Azzurro (2004), “há uma ausência a ser colocada em cena", e a "personagem" é a própria luz. Na primeira parte, essa combinação de luz e drama que leva à ação cria o espaço do "unspeakable home"; na segunda, gera as imagens cujos traços esmaecem com a iluminação intensa. O movimento lhe é consubstancial: "um eterno pêndulo de um clarão ao

O projeto Beckett \& Puppet é um exemplo desse nível 'figural' da obra de Beckett (Gorizia, 2016), cf. Marchiori, 2007. 
outro, de um polo de sombra ao outro [...], que não se direciona a um destino, mas, sim, à interrupção do movimento" (Di Marino, 2007, p. 178). Em suas notas de direção, Paolo Rosa enfatizava o "encontrar-se justamente no Neither, naquele movimento incessante, absurdo, oscilando de uma condição a outra, sem se estabilizar, nem em uma nem na outra" (Rosa, 2012, p. 223). Ao longo da ouverture orquestral, um facho de luz desce do alto; é a "personagem", no sentido supramencionado. Após desenhar um círculo, o facho se move, iluminando o nada (cf. Di Marino, p. 177-178; Pittaluga-Valentini, 2012, p. 222-241). Esta pesquisa confronta implicitamente a ideia de "figura", constituindo-a de acordo com novas estratégias a partir da ausência. Assim, ela surge como uma paisagem fluida, indefinível, do inconsciente, que pode assumir mil formas ou nenhuma (Pittaluga-Valentini, 2012, p. 222-241).

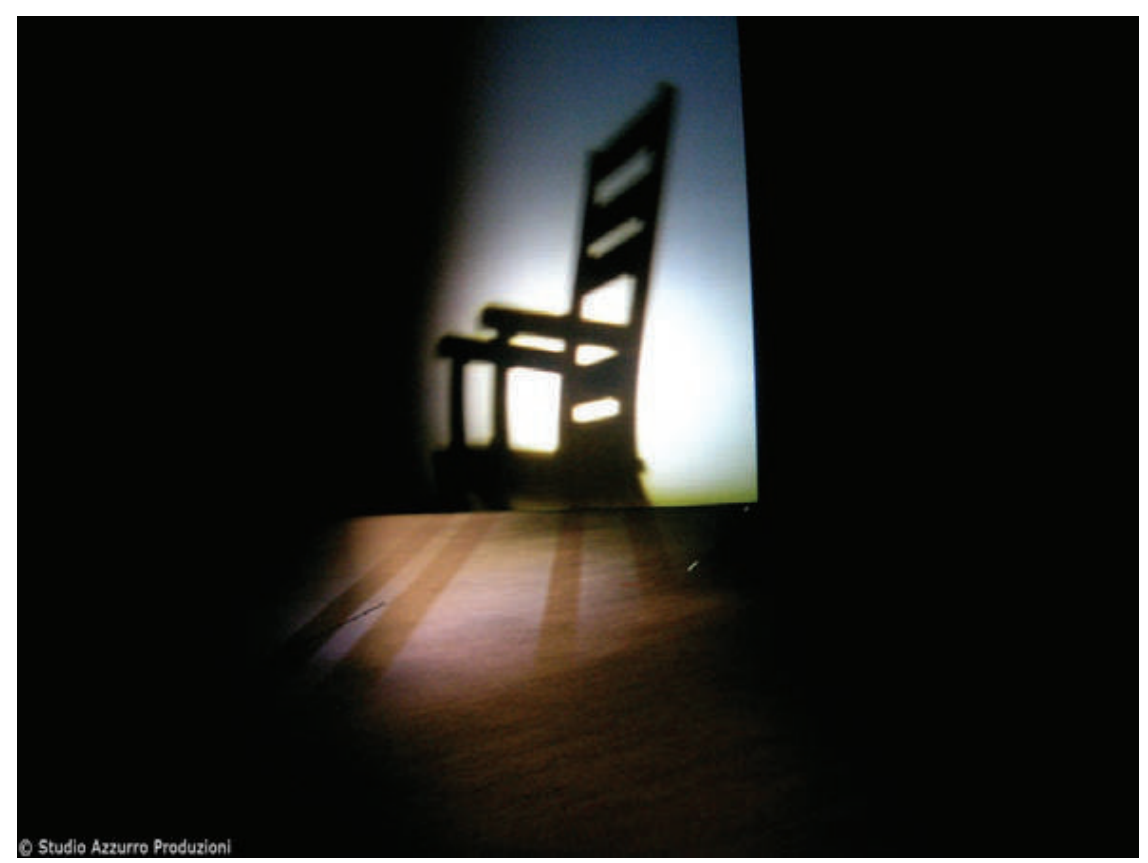

Figura 5 - Neither, Studio Azzurro, 2004. Foto e Arquivo: Studio Azzurro

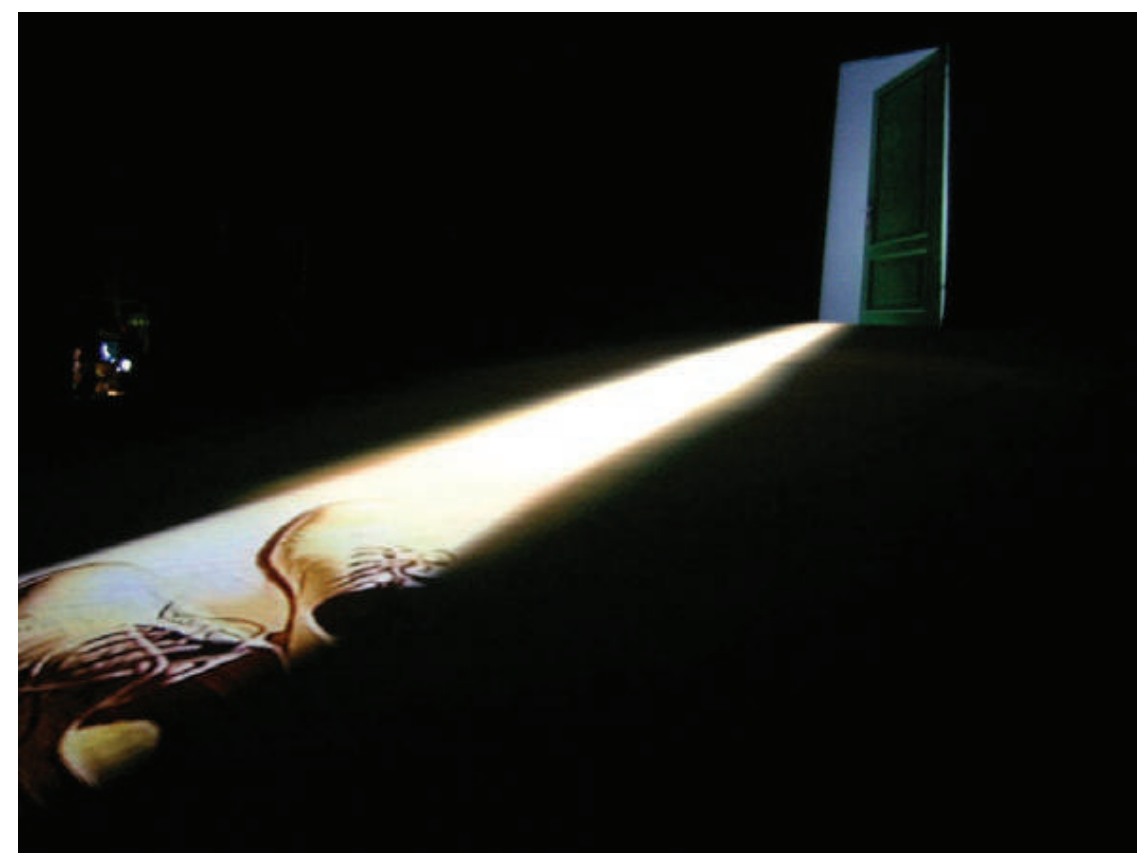

Figura 5B - Neither, Studio Azzurro, 2004. Foto e Arquivo: Studio Azzurro 
A luz recorta figuras extraídas de textos beckettianos, mas o pensamento flui também por meio de imagens recorrentes na experimentação do Teatro Imagem (ou do imaginário surrealista que o inspirava). A sombra da cadeira de balanço (o único objeto real) vazia, em movimento, "enseja a descoberta de imagens sempre diferentes" (Pittaluga-Valentini, 2012, p. 235). A imagem de um rato iluminado por um facho de luz desaparece para deixar espaço (ou "deixar o vazio") ao soprano, a única voz da obra, que aflora lentamente do poço da orquestra, aprisionada no escuro, como muitas das figuras beckettianas ${ }^{27}$.

São temas que ressoam no mais recente espetáculo de Berangère Vantusso, Alors Carcasse (2019) (Figura 6). O tema dramatúrgico do texto de Mariette Navarro (2011) é a existência da presença incerta, Carcasse, que está em todo lugar e em lugar nenhum, uma estranha figura caracterizada pela falta: 'falta' de contorno, de evolução, e também de cair no esquecimento para o que está além do limite sobre o qual tenta se perceber.

Curiosa figura vazia e fútil, de nome improvável e função nenhuma, mas que vive intensamente a experiência da imobilidade, presa no limiar de sua época. É como se ainda não existisse por inteiro e, portanto, como se diz, coloca-se ali, confusa, perturbada e bloqueada. ${ }^{28}$

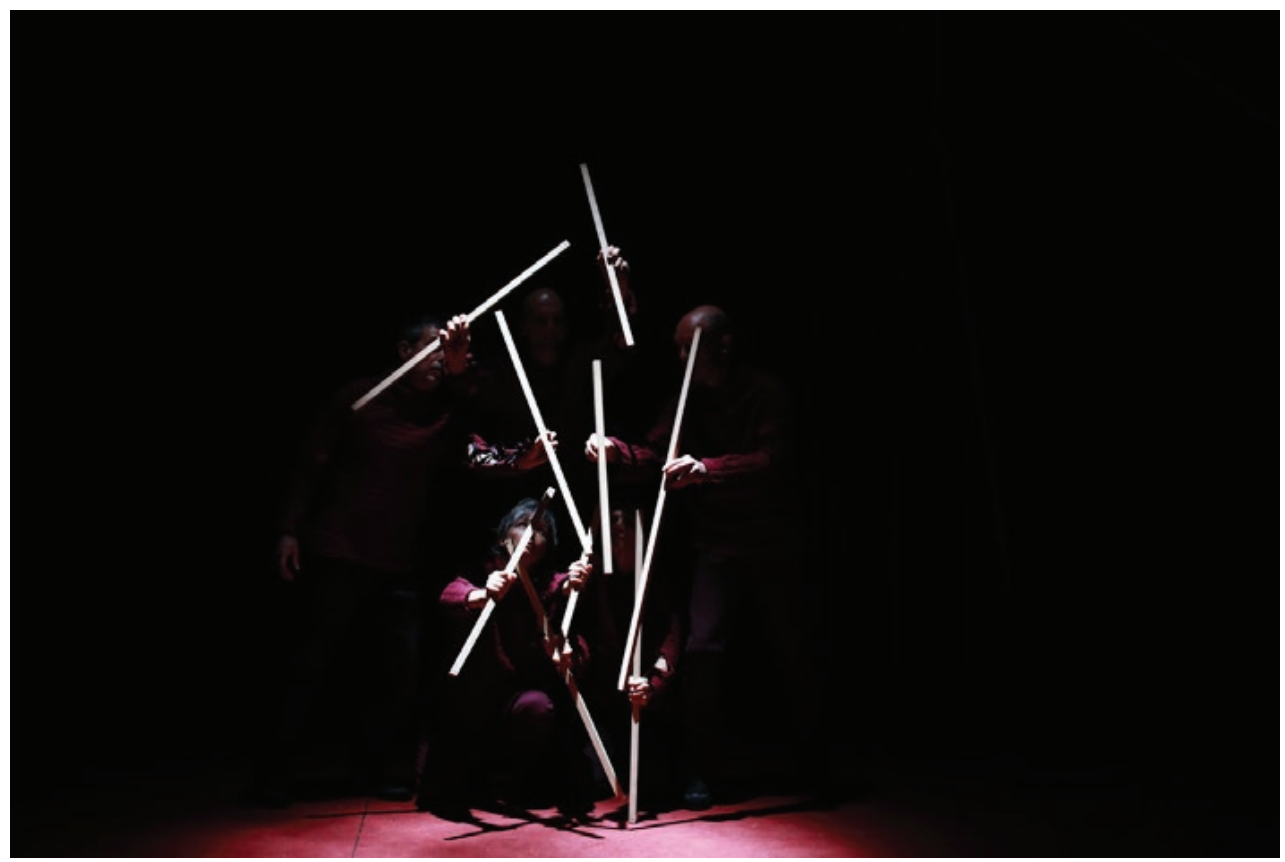

Figura 6 - Alors Carcasse, Compagnie Trois-Six-Trente, 2019.

Direção: Berangère Vantusso, Luci Berangère Vantusso. Foto: Ivan Boccara.

\footnotetext{
27 Vale a pena lembrar como esse mesmo texto seria o núcleo em torno do qual gira uma outra obra recente, de Romeo Castellucci, apresentada no Ruhrtriennale de 2014: a encenação de dimensões monumentais na qual o amplo espaço do Jahrhunderthalle de Bochum foi inundado de substância luminosa. Beckett também foi inspiração para Kris Verdonck, que parece solucionar a dicotomia humano/não humano no emprego de projeções em intensa interação com as presenças em cena. Le depepleur emerge, ainda de forma notável, como 'personagem' no belo ensaio de Georges Didi-Huberman dedicado a James Turrell, artista 'imprescindível' a qualquer dissertação contemporânea sobre iluminação (Didi-Huberman, 2001); cf. Grazioli, 2012.

28 Berangère Vantusso, folha de sala; "Curieuse figure vide et trouée, au nom improbable et sans fonction, mais qui vit intensément l'expérience de l'immobilité, bloquée sur le seuil de son époque. C'est comme s'il n'existait pas encore tout à fait et pourtant, comme on dit, il se pose là, trouble, dérange, fait obstacle"; espetáculo assistido no Festival de Charleville-Mézières 2019. (Tradução da autora do francês para o italiano, e nossa do italiano para o português).
} 
Vantusso opta por incorporá-la com base na 'dispersão', utilizando meios que disseminam sua presença no espaço. Assim, é mostrado ao espectador um lugar onde a presença invisível se coloca na fluidez de uma forma de presença difusa, que jamais pode ser delimitada. Evoca-se a Dança dos bastões (Figura 7) de Oskar Schlemmer, considerando as diretrizes das linhas de movimento que marcam a interação entre o corpo do dançarino e as leis do espaço: porém, enquanto para Schlemmer as formas que traduziam as linhas de movimento do corpo tendiam à centralização e à unidade, aqui, Carcasse é o invólucro de uma presença que não pode ser definida por coordenadas exatas. É como se a cena se configurasse de forma invertida, em negativo (no sentido fotográfico do termo), mostrando-nos na escuridão os rastros desses percursos $^{29}$.

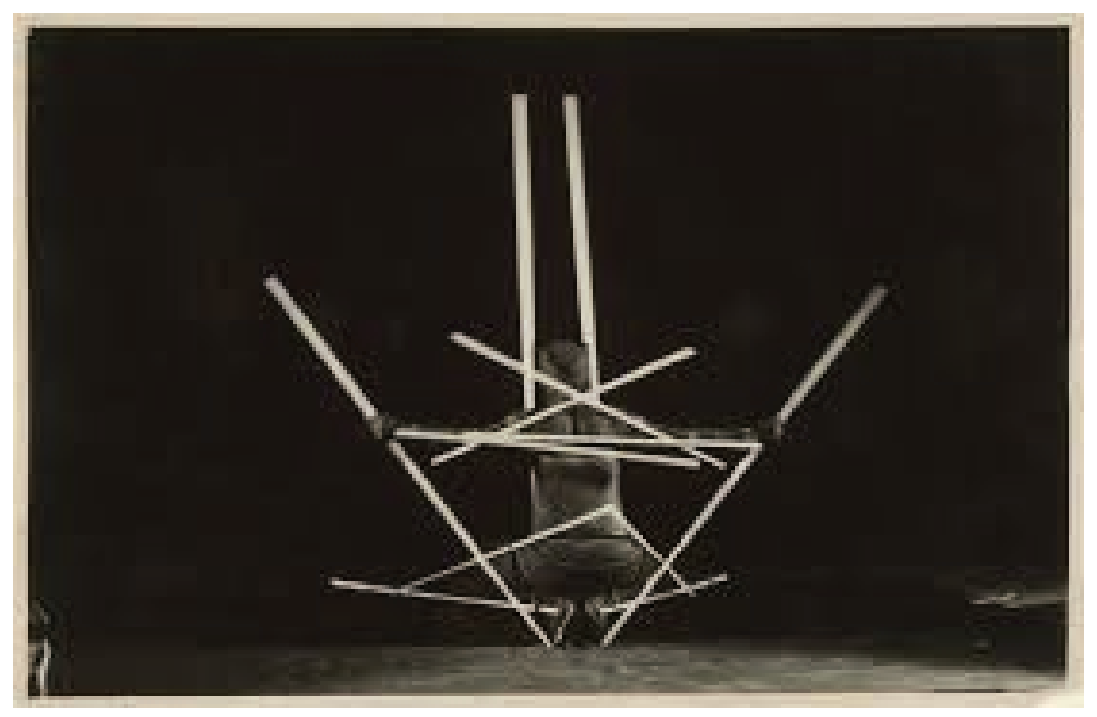

Figura 7 - Stäbetanz (Danza dei Bastoni), Oskar Schlemmer, 1927 ca. Foto: Rudolph Binnemann ${ }^{30}$

Se o diálogo da marionete com as artes figurativas recebe um impulso decisivo com a experimentação das Vanguardas Históricas, na segunda metade do século, essas conexões se estreitam e as metamorfoses nos corpos de luz e sombra também fascinam os artistas visuais cada vez mais ${ }^{31}$.

Nesse caso, usemos de exemplo a ocasião da recentíssima exposição de Chris-tian Boltanski, uma instalação que permite a experiência da dimensão performática de sua obra (colaboração de longa data com Jean Kalman ${ }^{32}$, mestre da criação de luzes). A Faire son temps acomoda o visitante de forma curiosa, fazendo-o passar por um espaço de teatro de sombras. A iluminação e as figuras unem forças para dar forma que compreende o fluxo mutável de memória - aos

\footnotetext{
29 Uma transparência evoca as cores da pintura de Rothko, também um pintor 'da luz'.

30 http://www.getty.edu/art/collection/objects/34708/rudolph-binnemann-stabetanz-of-oskar-schlemmer-german-about-1927/

31 Deles, citamos apenas alguns, sobre os quais refletimos mais frequentemente em ocasiões de seminários, já que suas obras estão ligadas à dimensão performativa: Claudio Bernardini, Fabrizio Corneli, Olafur Eliasson, William Kentridge, Mario Martinelli, Maurizio Nannucci, Alfredo Pirri, Simon Touaux, James Turrell...

32 Uma apresentação recente foi Pleine nuit, Paris, no Opéra Comique, 2016 (Christian Boltanski, Jean Kalman e Franck Krawczyk); esses artistas apresentarão também Fosse, programada para janeiro de 2020, também no Opéra Comique.
} 
motivos centrais de sua poética (cf. Boltanski, 2019; Boltanski, 1991): o rastro do passado, seus fantasmas transportados pela imagem da luz (fotografia), o confronto com a morte; temas que naturalmente encontram as dimensões do escuro, da sombra, do "chia-roscuro". Desde 1985, as obras de Boltanski são 'autoiluminadas', pois o artista re-nuncia ao uso das luzes do alto e imerge o espaço na penumbra; a iluminação é uma parte essencial de seus trabalhos. Notavelmente, nesse mesmo momento, Boltanski expõe seus primeiros Théâtres d'ombres (Figura 8) (Bienal de Paris de 1985), iniciando uma abertura em seu trabalho: o teatro de sombras é ligado "à l'idée de la mort, des fantômes, de la disparition. D'ailleurs, il suffit d'allumer la lumière et il n'y a plus rien» (Boltanskl, 2019, p. 44) 33

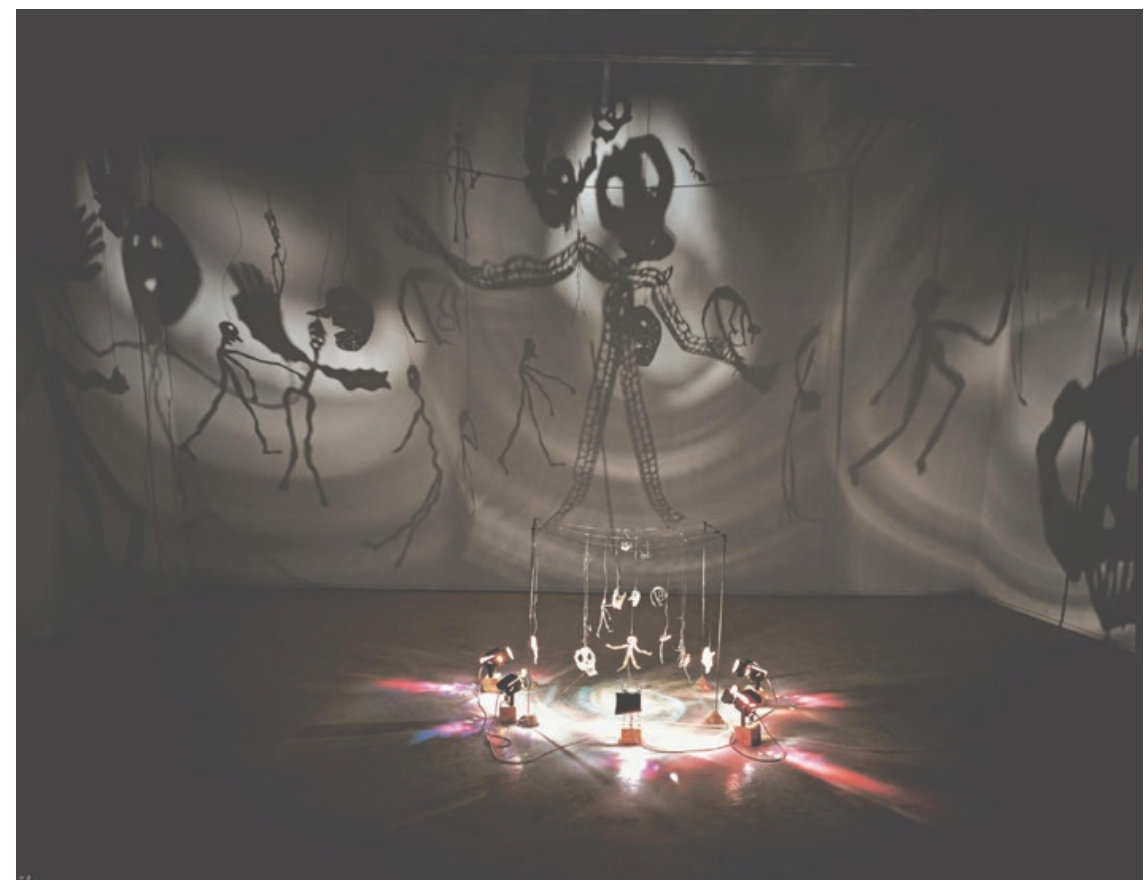

Figura 8 - Théâtre d'ombres, Christian Boltanski, 1984-1997, opera tridimensionale, installazione: luce, proiezione di 20 figurine su parete. Figurino: cartone, proiettori, piattoforma mobile, struttura in metallo, ventilatori, dimensioni variabili. Foto @ André Morain; @ Adagp, Paris, 2019.

\section{A montagem: recortar o visível}

Uma outra perspectiva de leitura possível das sobreposições entre luzes e marionetes deriva do princípio da montagem. É uma categoria antiga, que parece fluir em sigilo paralelamente a formas e procedimentos da narrativa linear subvertendo-os, bagunçando a lógica da ordenação e da composição do discurso lógico.

Um procedimento intrínseco à própria figura da Marionete, neste sentido exemplo do Grotesco ${ }^{34}$, composta de peças livremente acopláveis cujo potencial se revela justamente quando a lógica de 'reprodução' é alterada ou subvertida.

\footnotetext{
33 "à ideia da morte, de fantasmas, de desaparição. No entanto, basta apagar as luzes para que não haja mais nada".

34 Considerado como categoria estética e procedimento de composição; cf. Grazioli, 1999.
} 
Sendo parente próximo da colagem em sua versão do século XX, em nível formal (e técnico), esse procedimento foi reinventado e adequado ao cinema ${ }^{35}$, que o dispensa no meio 'luminoso' que lhe é consubstancial e, por sua vez, torna-se terreno de uma ampla faceta teatral de predominância visual. Nesse caso, os exemplos também podem ser bem variados.

No âmbito do Novo Teatro italiano, entre os anos 1960 e 1970, a experimentação passa frequentemente pelas nossas duas categorias, quais sejam a pesquisa de meios alternativos à presença tradicional do ator e o estudo do meio luminoso e projetivo (estratégias que se contrapõem aos dois principais pilares do teatro tradicional: o texto e o ator). Consideremos um artista como Mario Ricci (Figura 9), que começa ao lado do marionetista Michael Meschke; admira os dispositivos mecânicos de Harry Kramer e inventa um teatro de figuras original; mas, ao mesmo tempo, experimenta com o potencial da projeção luminosa de desconstruir personagens, ou, pelo contrário, de multiplicar as imagens de maneira vívida ${ }^{36}$. Em Edgar Allan Poe (1967), o filme como elemento cênico assume importância decisiva. Projetadas sobre um aparato fixo e fragmentado, as imagens cinematográficas mostram "aquilo que os espectadores já haviam visto e aquilo que poderiam ter visto", em seus componentes mais minuciosos: os detalhes das mãos, dos rostos e dos objetos utilizados. $O$ movimento deriva "da sobreposição e fragmentação de imagens cinematográficas e imagens reais" (Ricci, 1977, p. 225, 227-228) ${ }^{37}$ dos atores. A tridimensionalidade do espaço transforma o meio fílmico em código teatral.

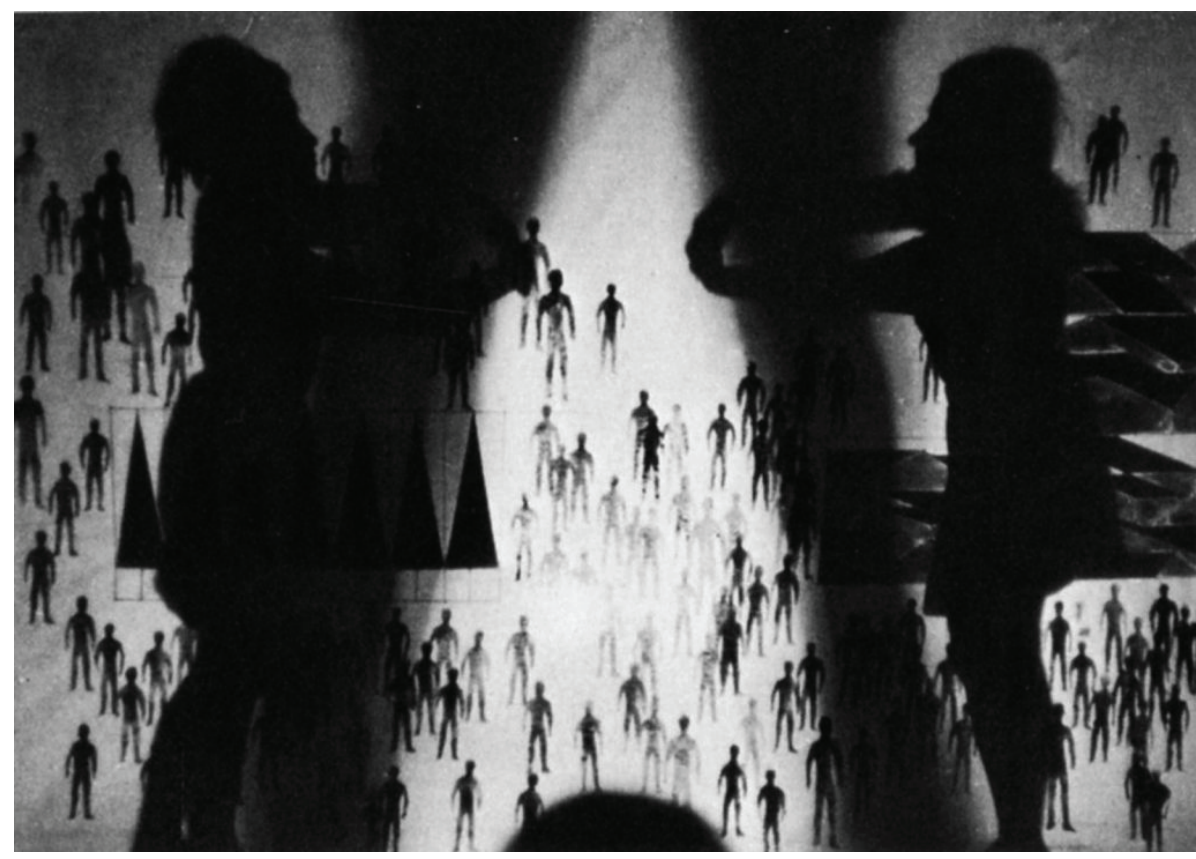

Figura 9 - I Viaggi di Gulliver, Mario Ricci, 1966. Foto: Pietro Galletti

\footnotetext{
35 A conexão entre o cinema e as marionetes tem sido produtiva desde a primeira metade do século XX; no que tange cf. "Puck. La marionnette et les autres arts" Les marionnettes au cinéma, 15, 2008.

${ }^{36}$ Referimo-nos aos focos relativos presentes no projeto Nuovo Teatro Made in Italy, encontrados no portal Sciami https://nuovoteatromadeinitaly.sciami.com/ mario-ricci-biografia-opere/.

37 cf. e Sinisi, 1983, p. 84.
} 
Em Salomé (1965) e As viagens de Guliver (1966), a sombra é utilizada como uma presença de ator "alterada". O filme retrata o ator e cria "um efeito de sobreimpressão destruindo a consistência íntegra do corpo humano, reduzindo-o [...] à condição fantasmagórica da sombra"; cria-se uma divergência entre a figura real e a transparência incorpórea da projeção: as imagens fílmicas surgem imperfeitas, transbordando os limites dos corpos e objetos que atingem "com uma fragmentação dinâmica que invade o ambiente, remodelando-o sobre a esteira do fluxo luminoso" (Sinisi, 1983, p. 84).

A paixão pela decomposição e recomposição, fragmentação e montagem, reflete o interesse de Ricci pelo universo das Marionetes: uma presença cênica que fundamentalmente põe em jogo a possibilidade de uma "montagem" diferente da figura do ator de carne e osso. Seus primeiros espetáculos foram: Movimento numero uno per marionetta sola (1962), Spettacolo di tre pezzi (1964), Movimento per marionetta sola numero due (1964), e Movimento uno e due (1965), títulos emblemáticos de sua pesquisa sobre os elementos "estruturais" do espetáculo38.

Também pela importância que Ricci the atribui com um olhar "autorretrospectivo", o encontro com o teatro de Harry Kramer ${ }^{39}$ durante o período acompanhando Michael Meschke em Estocolmo assume a característica de um "momento de revelação". Em atividade no âmbito da arte cinética, a partir de 1955, suas curtas apresentações privadas de elementos narrativos trazem à cena pequenas esculturas antropomorfas dotadas de movimento e são construídas com base em partituras sonoras, luminosas e mecânicas de extrema precisão. Diversos elementos do espetáculo assistido em Estocolmo comoveram Ricci: a composição por fragmentos; o fato de que o protagonista da ação fazia os mesmos movimentos que a escultura mecanizada cinética. Num espaço de dimensões reduzidas, os movimentos dessas figuras de cores vivas compunham a partitura da apresentação junto a sonoridades heterogêneas, alternando entre momentos estáticos e agitados. Germano Celant recorda que Kramer, naquele tempo, trabalhou por meio de "nebulosas filiformes, de ferro e aço, que possibilitam o uso de materiais heterogêneos de modo a conferir uma aparência físico-óptica às suas obras"40. A cena do artista alemão é um dispositivo cuja substância dramatúrgica se encontra no funcionamento dos materiais cênicos, que levam à ação dramática. Mas, na reevocação de Ricci, outro componente se destaca: o público participa com uma atenção rara de ver, fascinado pela repetição "infinita dos mesmos movimentos, alterados e alternados por luzes incrivelmente ágeis" ${ }^{41}$. Assim, o movimento é ativado pela luz. Ricci reconhece nessa experiência de espectador a motivação para experimentar com "certos materiais cênicos dotados de 'movimento' não exatamente mecânico, como no caso de Kramer". Buscamos não enfatizar as palavras de Ricci de forma convidativa à leitura desses "materiais cênicos" como o

\footnotetext{
38 O Spettacolo in tre pezzi foi apresentado junto a uma exposição de marionetes na Galleria Arco d'Alibert de Roma em 1964, cf. Mario Ricci, Teatro-rito e teatro-gioco, em Franco Quadri, L'avanguardia teatrale in Italia. Materiali (1960-1976), cit., p. 200-211: 203-204.

39 Cf. Ricci, 1970, p. 50-55; Kramer cria suas "marionetes" no início dos anos 1950. L'esclusa, vencedor do Leão de Ouro em Veneza na categoria de curtas-metragens em 1961. Sobre seu teatro mecânico cf. Metken, 1989).

40 M. Ricci, Collage per una automitobiografia, cit., p. 213.

${ }^{41}$ M. Ricci, Teatro-rito e teatro-gioco, cit., p. 201.
} 
fator luminoso. Tanto é que, imediatamente depois, o artista se refere a Craig e sua concepção de cena como dinamismo de luz e cor ${ }^{42}$.

Nesse mesmo contexto experimental, Memé Perlini empresta do cinema a arte do 'recorte' a fim de obter um fundamento diferente da imagem atoral: não faz uso da projeção, mas obtém sucesso na montagem visual isolando, por meio da luz, os 'fotogramas' do espaço cênico, detalhes dos corpos e dos objetos. A composição da marionete, regida pelo princípio do fragmento, da inversão e da decomposição, vem a coincidir com a montagem - também cinematográfica (cf. Grazioli, 2015).

Quanto à convergência entre a criação de luz para o teatro de figura e os procedimentos de montagem, vale relembrar a obra do brasileiro Renato Machado, A luz montagem (2015), onde o criador do desenho de luz conta sua experiência com as companhias Sobrevento e Pequod, que combina o pensamento e a prática da iluminação para marionetes com fortes referências ao mundo do cinema (Machado, 2015).

\section{A negra escuridão}

A escolha de "enquadramento" enquanto porção do visível a ser mostrada se dá, no teatro de marionetes, de forma complexa e rica de variáveis, uma vez que o ator se articula, nesse caso, na dupla presença, como marionetista e personagem. A questão da luz, e até mais intensamente a dimensão da escuridão, amplifica inevitavelmente as escolhas das diferentes possibilidades de o animador se fazer visível ou permanecer escondido, e, nesse caso, a escolha de qual modalidade adotar para permanecer no escuro ou adentrar o espaço da luz.

Após ter saído e se exposto no espaço visível da cena cada vez mais ao longo da segunda metade do século $X X$, exibindo a fragilidade da ilusão e a permeabilidade entre seu mundo e o mundo do objeto, atualmente, o marionetista "revisita" frequentemente a escuridão. Há muito, porém, essa escuridão mudou sua essência43: não é mais um poço escuro que engole quem está escondido, mas, sim, uma condição de 'alteridade' da matéria luminosa, uma cavidade geradora de imagens e sons. A escuridão tem sua própria voz; e, em muitos casos, constitui a origem da voz do marionetista.

O figurino, um elemento muito concreto, pode ser fundamental para auxiliar na revelação ou ocultação. Nessa dinâmica entre o revelado e o oculto, as vestes escuras podem ter um peso decisivo, correspondente à alternância do papel do marionetista entre manipulador e personagem ${ }^{44}$. O figurino se torna uma presença em si, que se insere no limite entre o ator e a personagem. Em Talita Kum (2012) (Figuras 10, 10B), de Riserva Canini, a cor preta no figurino funde e confunde as presenças da atriz e da personagem; presença, manipulação, as personagens se tornam um só graças a uma única atriz. A presença do Outro que se insere na esfera da identidade é fortíssi-

\footnotetext{
$42 \quad$ Ivi, pp. 201-202.

43 Para uma leitura sobre a escuridão no teatro, cf. Perruchon, 2016.

44 Refiro-me ao discurso em voz dupla nesse mesmo periódico, Plassard, Grazioli, 2018, p. 64-65.
} 
ma, tanto do ponto de vista físico e material quanto do ponto de vista dramatúrgico. O conhecimento técnico combinado ao cuidado dramatúrgico leva o espectador a se deparar constantemente com a dúvida quanto à essência das presenças: se é de carne e osso ou se é um simulacro, uma efígie, na luz ou no 'escuro'.

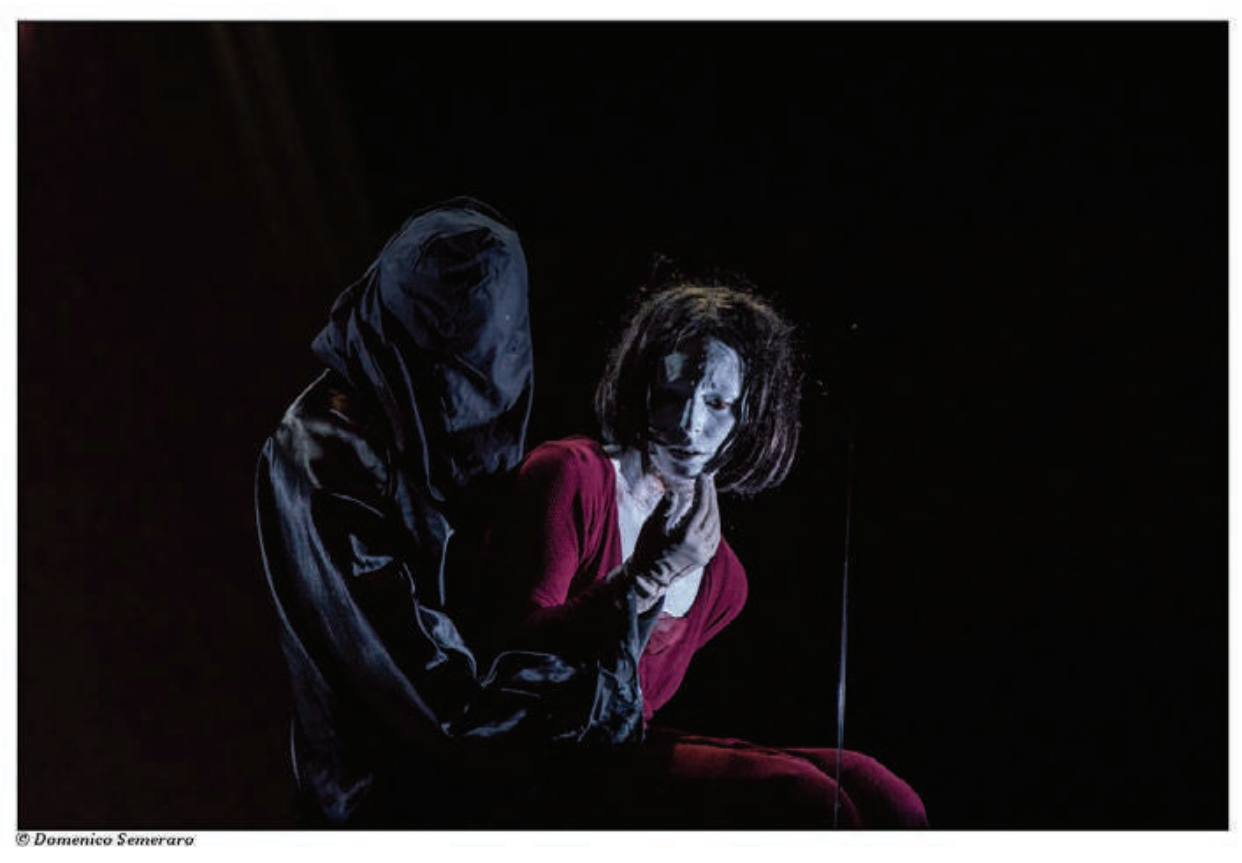

Figura 10 - Talita Kum, Riserva Canini, 2012. Foto: Domenico Semeraro

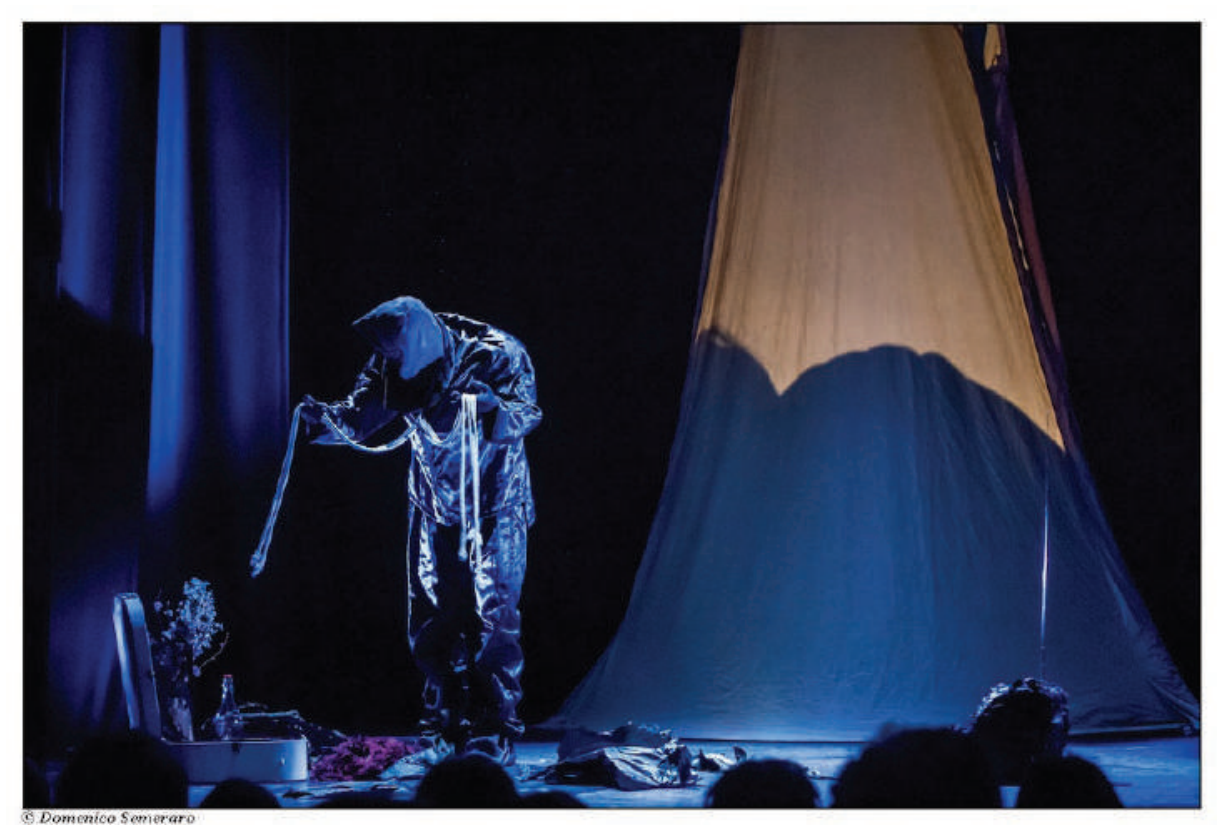

Figura 10B - Talita Kum, Riserva Canini, 2012. Foto: Domenico Semeraro

De todos os exemplos que trouxemos, fica evidente como o universo do desenho de luz é permeado pelo que antes era considerado o lado oposto: a sombra ou a escuridão. 
A magia é um território tradicionalmente habitado pela escuridão e um local de experimentação da luz, conquistada pelas marionetes nos últimos anos sob a definição de Magie Nouvelle ${ }^{45}$.

Em Le grand oeuvre (2019) (Figura 11), da companhia canadense La tortue noire, o marionetista é um alquimista que transmuta as presenças e, por sua vez, é atacado por elas; coloca-se no centro do diâmetro do espaço visível, no escuro. Os fenômenos luminosos acompanham a transmutação, o escuro torna visíveis as presenças ou coisas ocultas, e a luz parece tornar fértil a imagem.

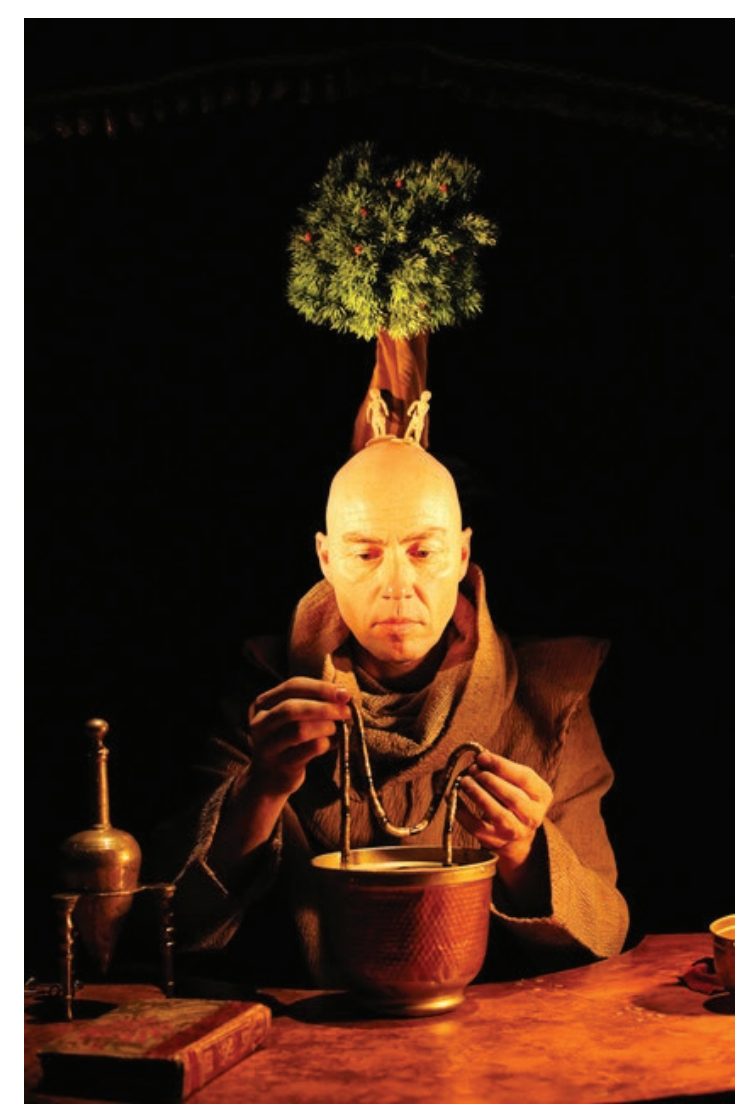

Figura 11 - Le Grand Oeuvre, La Tortue Noir, 2017. Foto: Patrick Simard

A associação entre "animação" e "animismo", evocada, por exemplo, por Max Legoubé, um artista qualificado em ambos os aspectos, na marionete e na Magie nouvelle (Legoubé, 2018, p. 43), não pode fugir desse contexto. O espetáculo $K$ (Figuras 12,12B) refere-se, em determinados versos, às temáticas de Alors Carcasse e do nada beckettiano (além da temática da perda kafkiana em referências únicas), introduzidas na memória do célebre ensaio de Kleist. K está em todo lugar e em lugar nenhum, é tudo e nada. A incerteza se torna a poesia da luz e da escuridão, suspendendo o estado de presença para compor a atmosfera. ${ }^{46}$

\footnotetext{
45 O já mencionado Poétiques de l'illusion foi dedicado a essas relações - no entanto, o papel da luz e da escuridão foi centralizado em apenas alguns momentos, sendo a Marionete a razão central da investigação; como referências para nossas reflexões, destacamos particularmente as contribuições de Julie Postel e Véronique Perruchon.

46 Compagnie Sans Souci, K (2019), assista ao teaser: https://vimeo.com/336188979 último acesso em 10 de dez. 2019.
} 


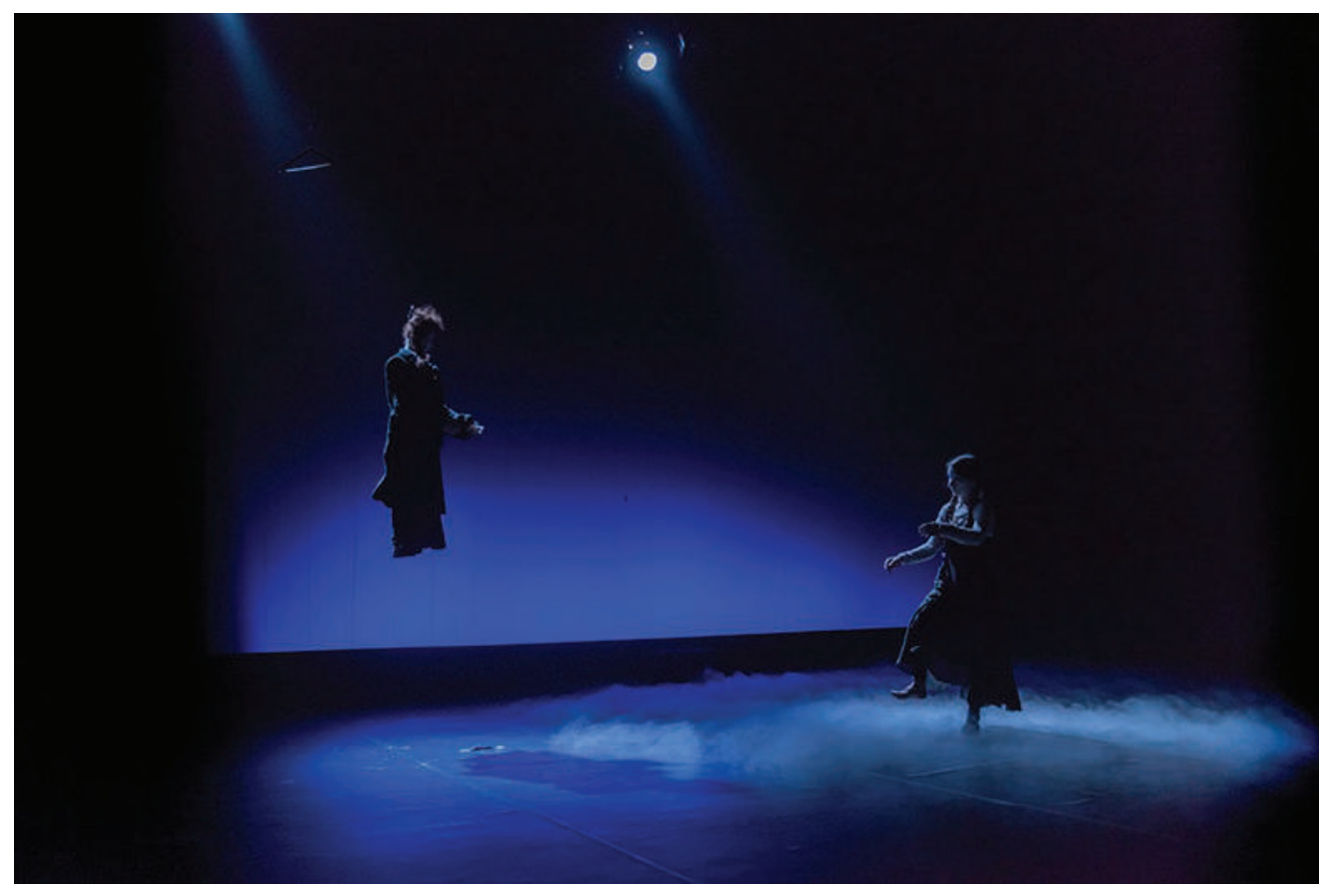

Figura 12 - K, Cie Sans Souci, 2019. Direção: Max Legoubé.Foto: Claude Boisnard

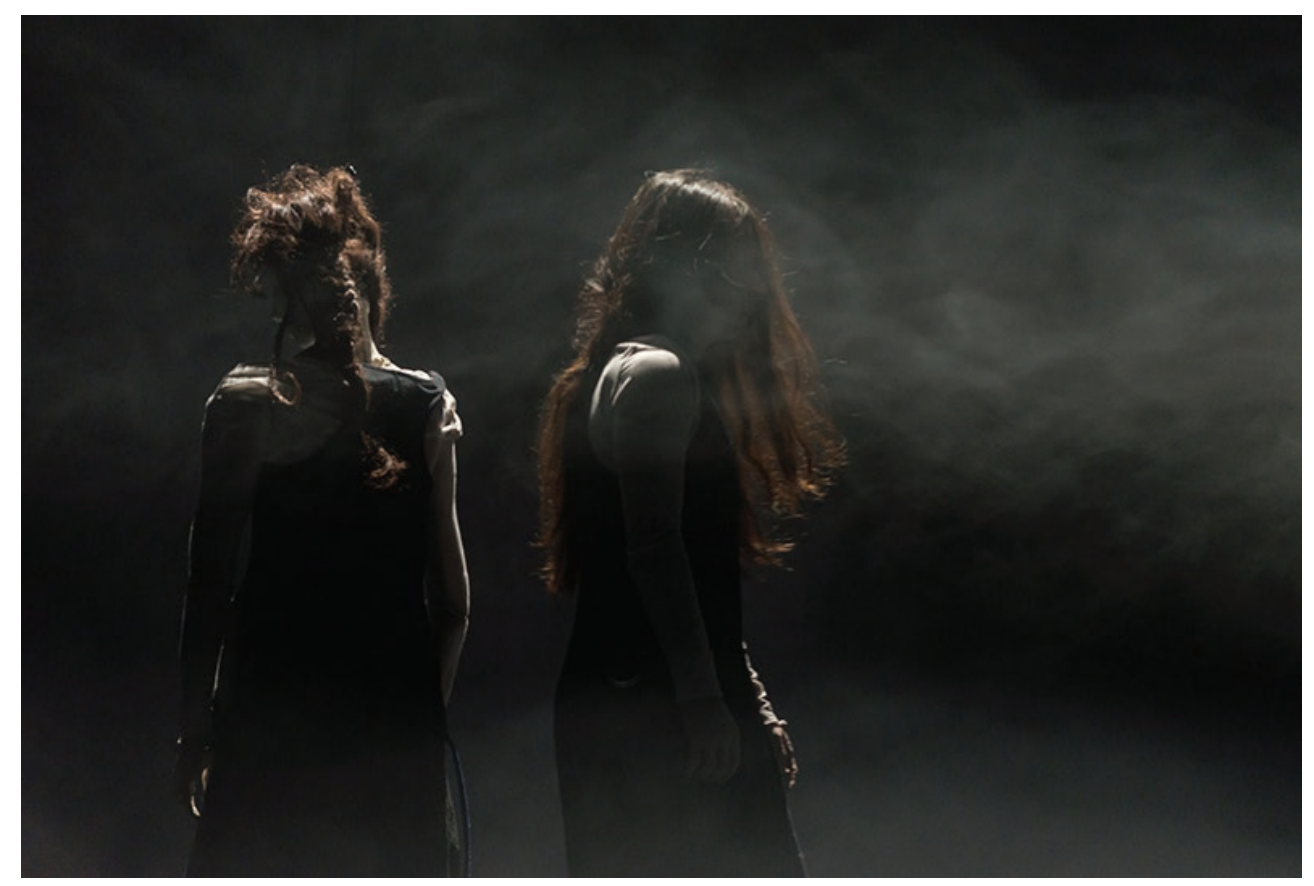

Figura 12B - K, Cie Sans Souci, 2019. Direção: Max Legoubé. Foto: Claude Boisnard 
Segundo Legoubé, os marionetistas contemporâneos e mágicos da "magie nouvelle" têm em comum "l'étrangeté et l'inévidence". Acrescentemos que a escuridão é cúmplice desses aspectos.

"O animismo pressupõe a multiplicidade nas modalidades de viver o mundo; no entanto, atribui a todos os seres o mesmo tipo de intencionalidade, que nós chamamos de "humana". O artista deve oferecer ao espectador o espaço de uma "divagação" (Legoubé, 2018, p. 43) ${ }^{47}$.

Essa essência divagante sinaliza uma condição de incerteza.

\section{Evaporar a imagem: status incerto de presença}

Nesse território de diálogo contínuo entre a poética e os procedimentos da luz e da marionete contemporânea, outra área muito fértil é a que podemos definir como a dos estados de passagem. Entendemos situações em que, graças à interação com a luz e a sombra, a matéria exibe sua própria constituição fragmentária ou em constante mudança, de modo a oferecer qualidades de presença 'instáveis'. Também neste caso, uma qualidade constitutiva da marionete no nível poético, sendo entre-deux, a concretização de uma condição de metamorfose, de deslizamentos semânticos ou de transfiguração, encontra correspondência em uma das áreas mais sugestivas e precursoras das aberturas atualmente implicadas pela luz. É um terreno formidável onde se confrontam a reflexão estética ${ }^{48}$, o pensamento teatral, as técnicas e as práticas de iluminação cênica. Não é por acaso que Didier Plassard comenta de "claro-escuro" como uma sugestão para definir a atmosfera onde vive o marionetista (cf. Plassard, 2018).

Numerosos são os artistas que, questionando-se sobre a dimensão efêmera constitutiva da arte performática -, encontram sua resposta no território fluido dos estados de transição, em materiais trabalhados com o uso da luz e da sombra: vapor, fumaça, água, gelo, fragmentos de vidro, todos os estados de transição da matéria são usados para representar a impermanência (Elise Vigneron, Impermanence) (Figura 13), a fragilidade da coerência (William Kentridge, Black Box ou Return. Daccapo ${ }^{49}$ ), a incerteza da percepção (Alice Laloy, Sfu.ma.to/Sous ma peau.).

\footnotetext{
47 L'animisme suppose la multiplicité des manières d'habiter le monde, mais attribue à tous les êtres le même genre d'intentionnalité, que nous dirions 'humaine. (Tradução da autora do francês para o italiano, e nossa do italiano para o português). A respeito do efeito da ausência, do corpo em fragmentos e do corpo disfarçado, ver o ensaio lúcido de Julie Postel (2018).

48 A referência é à "estética das atmosferas", sobre a qual mencionamos os estudos de Tonino Griffero e Gernot Böhme. Tantos outros artistas que não citamos por razões de espaço, dentre os quais: Les Anges au plafond (em especial pelo uso da sombra em White dog), Ilka Schönbein (pela luz que desintegra a imagem e o 'recorte' visual), Plexus polaire (Yingvild Aspeli, pelo poder visionário da interação entre luz/escuridão e figura), Magali Chouinard (pela cor e materialidade do preto e branco, por exemplo no Ame nomade); e a lista continua.

49 Cfr. Grazioli, 2011.
} 


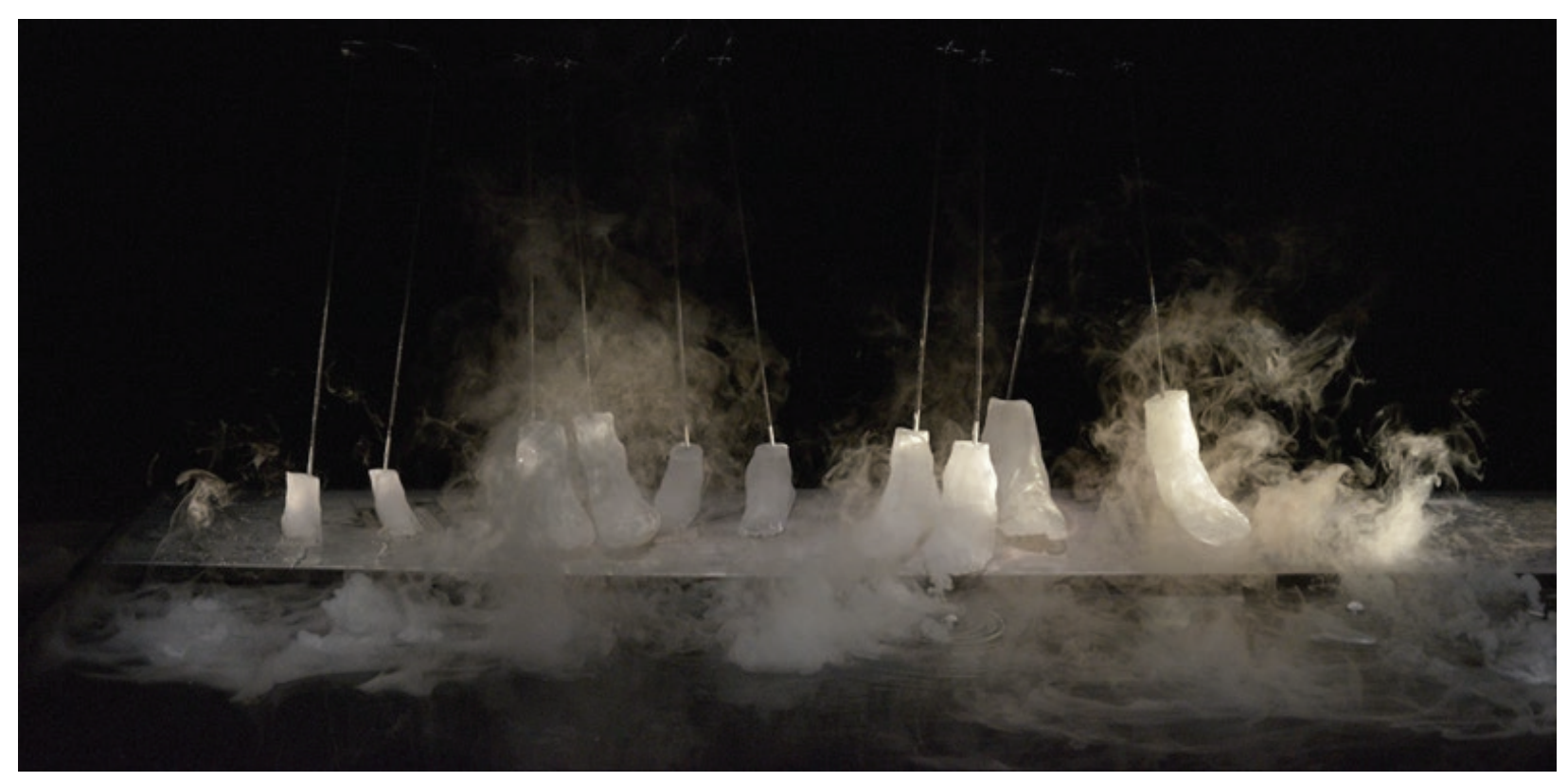

Figura 13 - Impermanence, Théâtre de l'Entreouvert, 2013. Direção: Elise Vigneron. Foto: Eric Bourret

Elise Vigneron eleva poderosamente a substância 'líquida' da arte das marionetes nas figuras de gelo, um material que interage com a luz, destinado a derreter, tornando-se o meio de transmutação da imagem e da presença que ela representa dramaturgicamente; a marionete evapora e declara sua natureza de luz, seu status próximo ao invisível na materialidade de uma nebulosa imaterial (Impermanence, Anywhere).

Em Sfu.ma.to/Sous ma peau (Figura 14) (Alice Laloy, Cie S'appelle reviens), à luz é confiada a tarefa de traduzir a ideia dos estados de passagem (físicos, emocionais, perceptivos) na materialidade da atmosfera como um território de incerteza da percepção e, portanto, de nosso conhecimento do mundo, do fluxo dos fenômenos, contra o enfoque na linearidade do pensamento e na univocidade do real. A partir da ideia de Sfumato em Leonardo e na pintura, Alice Laloy trabalha nas ambiguidades, visuais e auditivas, de nossa comunicação habitual. Como também no caso de Elise Vigneron, somos chamados como espectadores a colher fragmentos, a mudar perspectivas, a ler a realidade de acordo com as infinitas possibilidades que o corpo da Marionete sempre nos ensinou. 


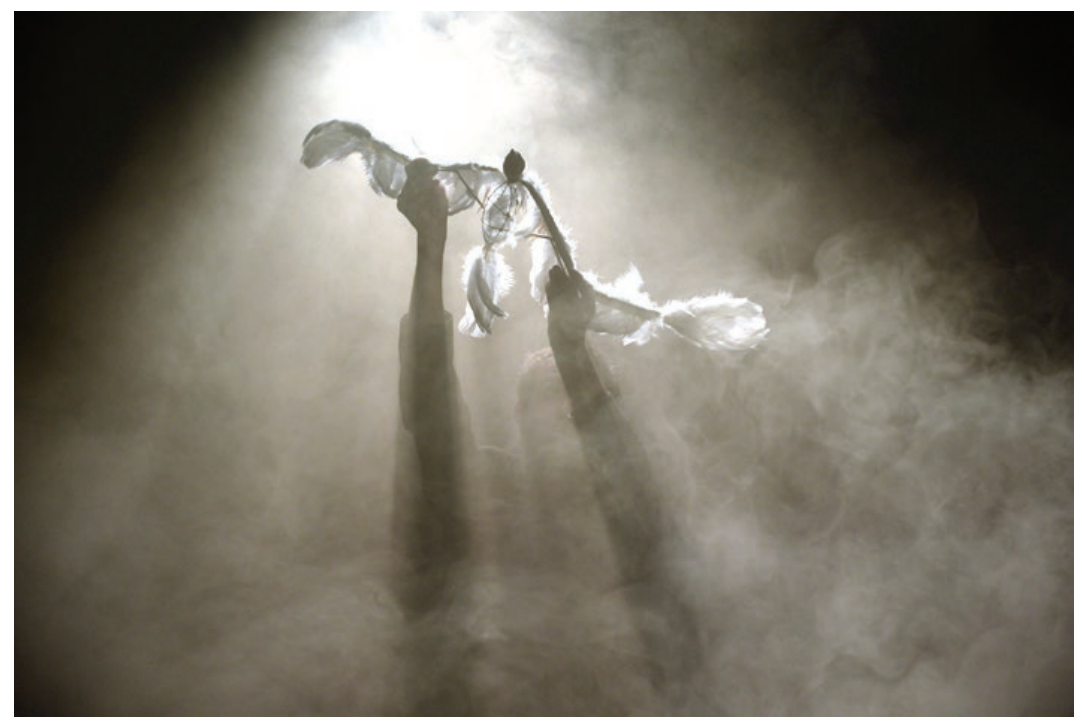

Figura 14 - Sous ma peau / Sfu.ma.to, La Cie S'appelle Reviens, 2015. Direção: Alice Laloy. Foto: Elisabeth Carecchio

"Contra o foco" trabalham a alusão, o 'esfumaçado' e evaporado, o sangramento, o foco suave, que exigem a evocação e a conclusão da imagem graças à mente e aos olhos do espectador (e também à sua memória ou emoção).

No entanto, a distinção tradicional Ilusão/Alusão, historicamente sancionada desde os pronunciamentos de renovação da arte teatral no contexto simbolista (isto é, contra o realismo e sua evolução no Naturalismo) parece hoje genérica demais: se é verdade que a luz clara e o design preciso reduzem a dúvida sobre a veracidade do que captamos com nossos olhos, a matéria trabalha a imagem no sentido de um desmoronamento, reabrindo a brecha da margem para a imaginação.

Essa condição é um valioso exercício de mobilidade e relativização: a realidade não é unívoca, a verdade é múltipla, o humano é apenas um dos muitos aspectos de um universo complexo ${ }^{50}$.

Esses conhecimentos e dúvidas são, há muito tempo, patrimônio das artes da marionete, que as revelam mais do que nunca em suas concepções contemporâneas, ao deixarem os limites do corpo para experimentarem uma presença difusa.

Nesse contexto, o trabalho de Renaud Herbin, diversificado em relação a resultados formais, mas profundamente coeso do ponto de vista da concepção, constitui um observatório interessante. Tomemos, por exemplo, Milieu (Figura 15 e 16), também inspirado em Beckett (le Depepleur), no qual a matéria engole a marionete como areia movediça. A luz e a escuridão, neste caso, parecem absorver, com a marionete,

o movimento e o próprio marionetista, deixando um vazio no "lugar", um milieu sem centro. Esse escopo é amplificado pela instalação resultante, Milieu et alentours, uma

\footnotetext{
Talvez não seja incongruente relacionar essas áreas da marionete com o pensamento do pós-humanismo, uma abordagem da realidade além do humano: tratam-se de territórios da cultura contemporânea que seriam interessantes de se relacionar com a marionete, mas também com o poder da mutabilidade a perspectiva posta em jogo pela luz e sombra; cf., entre outros, os estudos de Roberto Marchesini.
} 
versão articulada no espaço, que mantém seu centro na estrutura original, mas o desafia por outros lugares, caracterizados por materiais como areia, pedra, água, espelho: todos materiais que interagem com a luz e a sombra, movendo o centro dentro do fluxo do que percebemos, caminhando no espaço ${ }^{51}$.
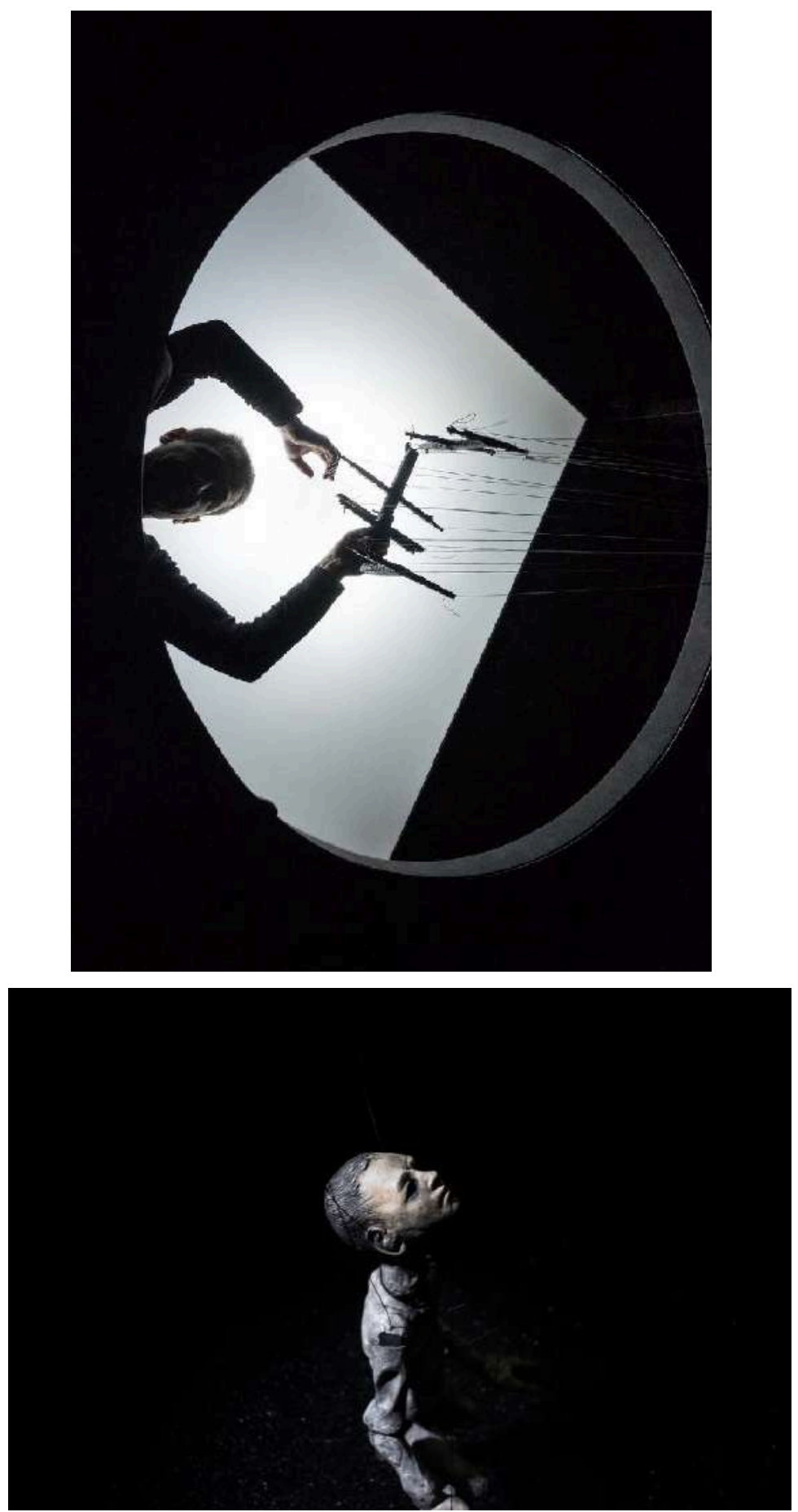

Figura 15 - Milieu, Renaud Herbin, 2017. Foto: Benoît Schupp

\footnotetext{
51 Na segunda instalação, os espectadores se movem no espaço. Cf. http://www.renaudherbin.com/milieu, último acesso em 10 dez. 2019. Outra criação recente de Renaud Herbin, At the still point of the turning world (Figura 16) sugere uma marionetização do espaço, sugerindo também neste caso a mudança de um suposto centro para uma presença difusa.
} 


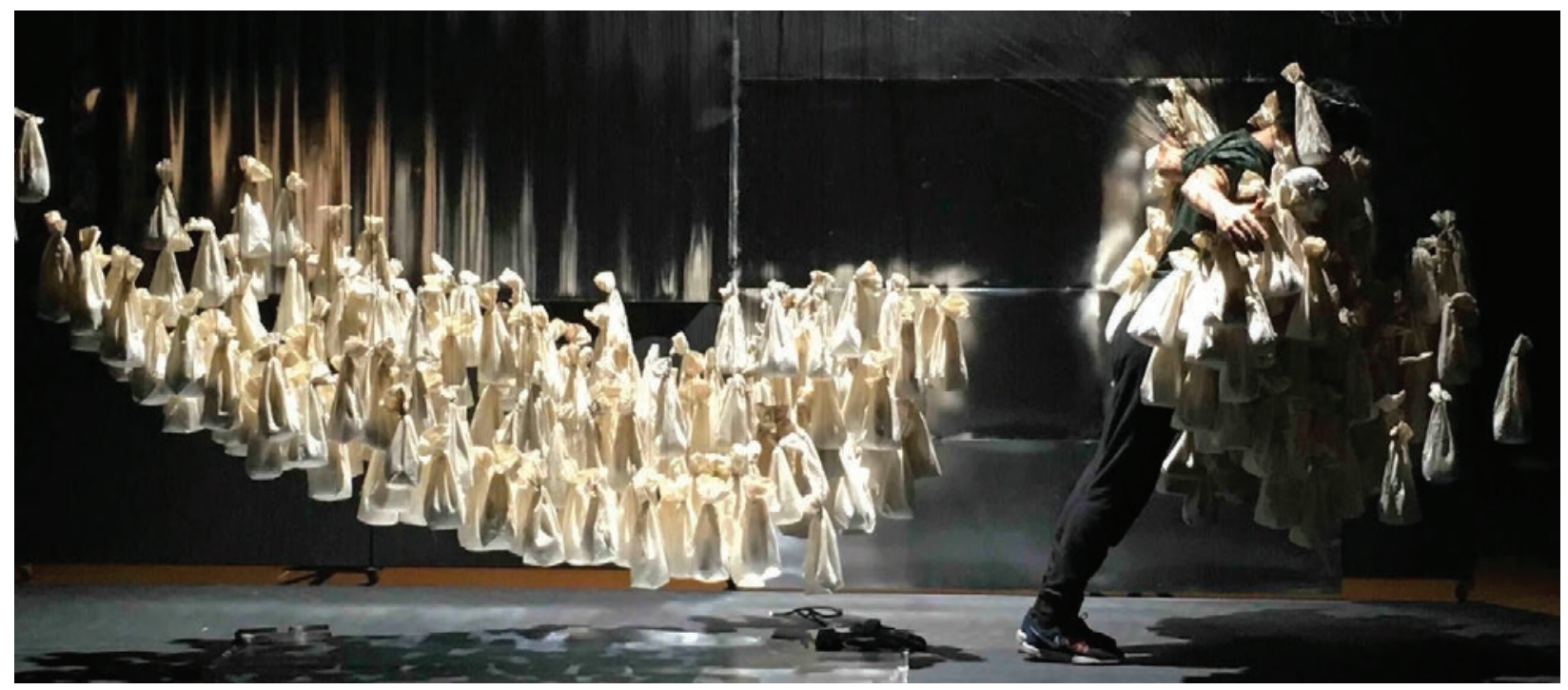

Figura 16 - At the still point of the turning world, Renaud Herbin, 2019. Foto: Benoit Schupp

Finalmente, a matéria em seu estado 'passageiro' ou fluido também pode atuar como um meio que dá tempo musical às figuras.

Uma variação divertida e muito leve desses temas é a Symphonie phantastique (Figura 17 e 17B) de Basil Twist. Aqui, a água, um ambiente que exige que os manipuladores realizem trabalhos difíceis de manipulação (os marionetistas atuam com figuras submersas num grande tanque d'água fazendo uso de varas ${ }^{52}$ ), transfigura a presença material graças à criação de luz colorida, combina o figurativo e o abstrato, a imanência das figuras e a evocação no brilho da luz.

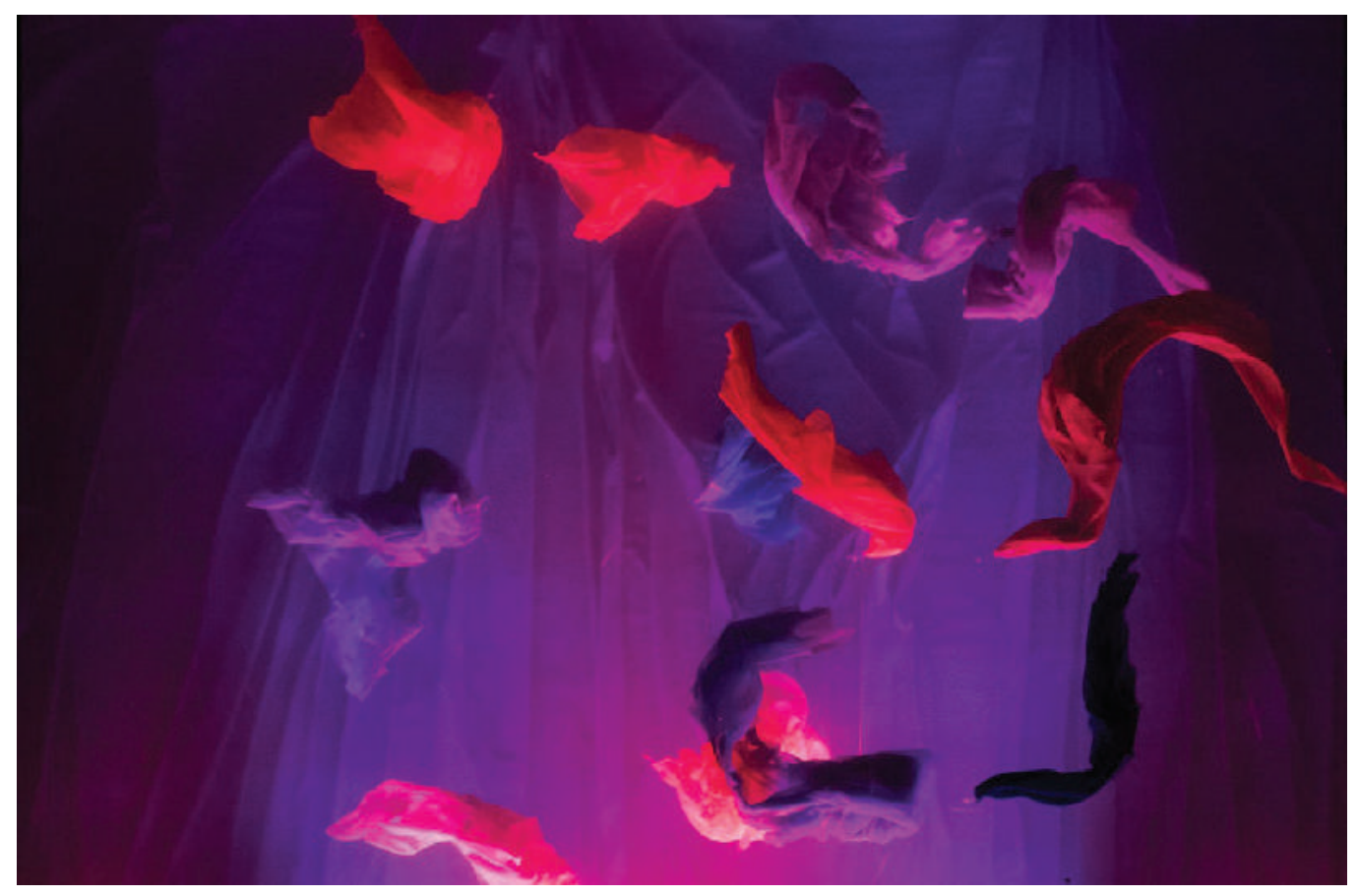

Figura 17 - Symphonie Fantastique, Basil Twist, 1998-2019. Foto: Richard Termine

52 Um curto vídeo de sua realização: https://www.youtube.com/watch?v=fgkU2Vm3qOE; último acesso em 10 dez. 2019. 


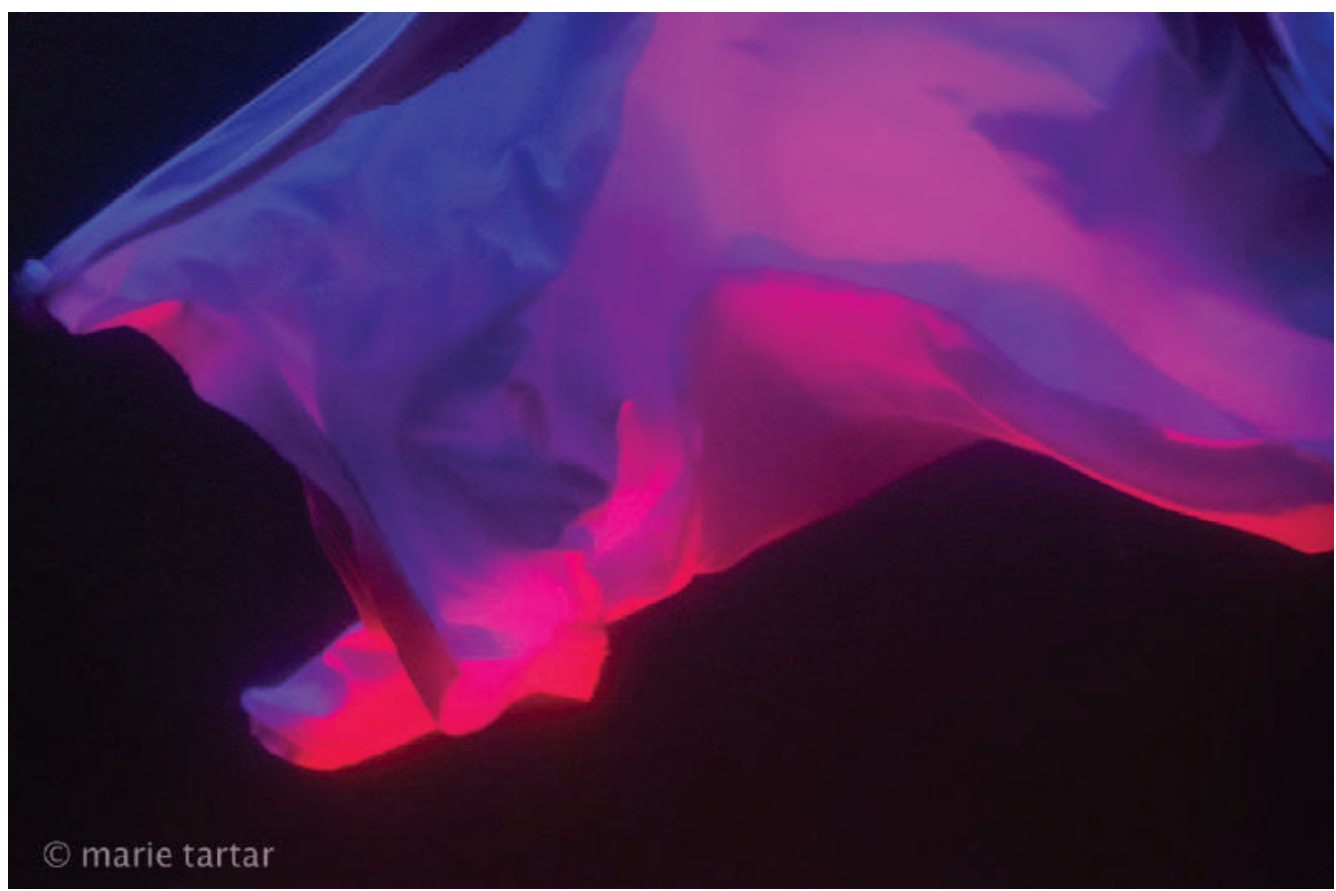

Figura 17B - Symphonie Fantastique, Basil Twist, 1998-2019. Foto: Marie Tartar

\section{Referências}

APPIA, Adolphe. Feuvres complètes. Éd. par Marie L. Bablet-Hahn, Genève: L'âge d'homme, 4 voll., 1983-1992, II, p. 351.

BOLTANSKI, Christian. Faire son temps. Catalogo della mostra. Paris: Centre Pompidou, 2019.

BOLTANSKI, Christian. Inventar, hrsg. von Uwe Schneede. Hamburg: Hamburger Kunsthalle, 1991.

CONATI, Marcello. Aspetti della messinscena nel Macbeth di Verdi. Nuova Rivista Musicale Italiana. 1981, n. 3, p. 374-404.

CRAIG, Edward Gordon. The Actor and the Übermarionette. The Mask. 2, April, 1908, p. 4-18

DIDI-HUBERMAN, Georges. L'homme qui marchait dans la couleur. Paris: Les éditions de Minuit, 2001.

DI MARINO, Bruno (a cura di). Tracce, sguardi e altri pensieri. In: Studio Azzurro. Videoambienti, ambienti sensibili. Milano: Feltrinelli, 2007.

GAUDÉ, Laurent. Robert Wilson et la "super-marionnette" ou la dépossession consen- 
tie au comédien. In: Alternatives Théâtrales. 65-66, novembre 2000, p. 62-63.

DEPERO, Fortunato. Colori, «Gli Avvenimenti», 1916.

GONZAGA, Pietro. Information à mon Chef ou éclaircissement con-venable du décorateur-théâtral Pierre Gothard Gonzague sur l'exercise de sa profes-sion, Saint Pétersburg: de l'Imprimerie d'Alex Pluchart, 1807; trad. it. in Pietro Gonza-ga, La musica degli occhi. Scritti di Pietro Gonzaga, a cura di Maria Ida Biggi, Firenze: Olschki, 2006, p. 45-96.

GOUHIER, Henri. Le théâtre et l'existence. Paris: Vrin, 2004 (prima edizione Paris, Aubier, 1952).

GOUHIER, Henri. L'essence du théâtre. Paris: Aubier-Montaigne, 1968 (Nouvelles édition avec dédicace « à Gaston Baty »); prima edizione, 1943.

GRAZIOLI, Cristina. Lo specchio grottesco. Marionette e automi nel teatro tedesco del primo Novecento. Padova, Esedra, 1999.

GRAZIOLI, Cristina, Luce e ombra. Storia, teorie e pratiche dell'illuminazione teatrale, Roma-Bari: Laterza, 2008.

GRAZIOLI, Cristina. Acteurs de lumière. In : Puck. La marionnette et les autres arts. Les marionnettes au cinéma, n. 15, 2008, p. 11-22.

GRAZIOLI, Cristina. Performing Black Box. William Kentridge o la luce dell'ombra, in «Mantichora», n. 1, dicembre 2011, p. 379-404

GRAZIOLI, Cristina. Cavità di luce, riflessid 'ombra: poetiche dell'assenza e drammaturgie della luce. In: On presence, a cura di Enrico Pitozzi. Culture Teatrali, n. 21, 2012, p. 41-58.

GRAZIOLI, Cristina. Mensch, (Tod) und Kunstfigur: fi gures de la Mort et de l'altérité dans les réflexions de Rainer Maria Rilke et Oskar Schlemmer, Actes du Colloque, Surmarionnettes et mannequins: Craig, Kantor et leurs héritages contemporains. Charleville-Mézières 15-17 mars 2012, Paris: L'Entretemps, 2013, p. 153-172.

GRAZIOLI, Cristina. Espaces partagés: les relations entre lumière, projection, espace. Réflexions et expérimentations (1910-1930) in Séances des années folles. Salles, techniques, pratiques, Paris, Kinétraces éditions (atti del seminario giugno 2017, in corso di pubblicazione).

GRAZIOLI, Cristina, Proiezione, spazio, materia: comporre e scomporre con la luce in Valentina Valentini, Nuovo Teatro Made in Italy 1963-2013, con saggi di A. Barsotti, C. Grazioli, D. Orecchia. Roma: Bulzoni, 2015, p. 325-357. 
JAMAIN, Claude. Richard Teschner, le magicien de la marionnette. In : Poétiques de l'illusion. Dialogues contemporains entre marionnette et magie. Alternatives Théâtrales: Liège 2018, p. 84-85.

LEGOUBÉ, Max. Un espace pour la divagation. In : Poétiques de l'illusion. Dialogues contemporains entre marionnette et magie. Alternatives Théâtrales: Liège 2018, p. 42-44.

MACHADO, Renato. A luz montagem. Curitiba: Prismas, 2015.

MARCHIORI, Fernando, (a cura di). Beckett \& Puppet. Studi e scene tra Samuel Beckett e il teatro di figura, Corazzano (PI): Titivillus, 2007.

MAETERLINCK, Maurice. Menus Propos. Le théâtre. La jeune Belgique. Septembre 1890, p. 331-336.

METKEN, Gunther. Entre la marionnette et la machine. Le théâtre mécanique de Harry Kramer. Puck. La marionnette et les autres arts. Les plasticiens et la marionnette, n. 2, 1989, p. 54-56.

MILDENBERGER, Marianne. Film und Projektion auf der Bühne, Emsdetten: Lechte, 1961.

MAURIN, Frédéric, Spectral Spectacle. In : Puck. La marionnette et les autres arts. Images virtuelles, 9, 1996, p. 27-31.

NAVARRO, Mariette. Alors Carcasse. Paris: Cheyne, 2011.

PERRUCHON, Véronique. Noir. Lumière et théâtralité, Lille: Presses Universitaires du Septentrion, 2016.

PITTALUGA, Noemi; VALENTINI Valentina (a cura di). Studio Azzurro. Teatro, Roma: Contrasto, 2012.

PLASSARD, Didier (éd.). Les mains de lumière. Anthologie des écrits sur l'art de la marionnette. Charleville-Mézières: Institut International la Marionnette, 1996.

PLASSARD, Didier ; GRAZIOLI, Cristina, La marionnette, ou la mimésis complexe \& La complexité des « figures » dans le théâtre en tant que "mimesis » (Convegno UNIMA, Targoviste, giugno 2017). Urdimento - Revista de Estudos em Artes Cênicas, Florianópolis, v. 2, n. 32, 2018, p. 56-72.

http://www.revistas.udesc.br/index.php/urdimento/article/

view/1414573102322018056B/8919 
PLASSARD, Didier. Illusion continue et illusion discontinue sur la scène des marionnettes. In : Poétiques de l'illusion. Dialogues contemporains entre marionnette et magie. Alternatives Théâtrales: Liège 2018, p. 12-17.

POSTEL, Julie. Dissimuler à vue le corps en scène: effets d'absence et morcellement des présences scèniques. In : Poétiques de l'illusion. Dialogues contemporains entre marionnette et magie. Alternatives Théâtrales: Liège 2018, p. 56-59.

Puck. La marionnette et les autres arts. Les marionnettes au cinéma, 15, 2008.

RICCl, Mario. Parentesi sull'uso del cinema e frantumazione dell'immagine, in Franco Quadri, L'avanguardia teatrale in Italia. Materiali (1960-1976). Einaudi: Torino 1977, 2 voll., I, p. 225-236,

RICCl, Mario. Teatro-rito e teatro-gioco. In: Franco Quadri, L'avanguardia teatrale in Italia. Materiali (1960-1976), cit., p. 200-211,

RICCl, Mario. A partire da zero [autobiografia] di Mario Ricci, a cura di G. Celant, «Sipario», n. 296, dicembre 1970, pp. 50-55 (poi Collage per una automitobiografia (a cura di G. Celant). In F. Quadri, L'avanguardia teatrale in Italia. Materiali (1960-1976), cit., p. 212-221)

RILKE, Rainer Maria. Ancora una parola sul valore del monologo (lettera aperta a Rudolf Steiner, in Rainer Maria Rilke, Scritti sul teatro, a cura di Umberto Artioli e Cristina Grazioli, Genova: Costa \& Nolan, 1995, pp. 69-71. Ed. orig. Noch ein Wort über den Wert des Monologes (Offener Brief an Rudolf Steiner). In : «Dramaturgische Blätter», 40, 8. Oktober 1898, ora in Rainer Maria Rilke, Sämtliche Werke, Rilke-Archiv und R. Sieber-Rilke, éd. E. Zinn, Insel, 1975 (prima edizione in 6 volumi 1955-1966), 12 voll., v. 10, p. 439-442.

RILKE, Rainer Maria. Appunti sulla melodia delle cose. In: Rainer Maria Rilke, Scritti sul teatro, cit., p. 75-84. Ed. orig. Notizen zur Melodie der Dinge [1898]. In: Rainer Maria Rilke, Sämtliche Werke, cit., p. 412-425.

Paolo Rosa. Note di regia. In: Noemi Pittaluga, Valentina Valentini (a cura di), Studio Azzurro. Teatro, Contrasto: Roma 2012.

SINISI, Silvana. Dalla parte dell'occhio. Esperienze teatrali in Italia (1972-1982). Roma: Kappa, 1983. 